\title{
Energy and Exergy Analyses of Medium Temperature Latent Heat Thermal Storage with High Porosity Metal Matrix
}

\author{
Ashish Kumar ${ }^{a}$, Sandip K Saha,** \\ a Department of Energy Science and Engineering, Indian Institute of Technology Bombay, \\ Powai, Mumbai- 400076, INDIA. \\ ${ }^{\mathrm{b}}$ Department of Mechanical Engineering, Indian Institute of Technology Bombay, Powai, \\ Mumbai- 400076, INDIA.
}

\begin{abstract}
Thermal energy storage system in a concentrating solar plant (CSP) reduces the gap between energy demand and supply caused by the intermittent behaviour of solar radiation. In this paper, detailed exergy and energy analyses of shell and tube type latent heat thermal storage system (LHTES) for medium temperature solar thermal power plant $\left(\sim 200^{\circ} \mathrm{C}\right)$ are performed to estimate the net useful energy during the charging and discharging period in a cycle. A commercial-grade organic phase change material (PCM) is stored inside the annular space of the shell and the heat transfer fluid (HTF) flows through the tubes. Thermal conductivity enhancer (TCE) in the form of metal matrix is embedded in PCM to augment heat transfer. A numerical model is developed to investigate the fluid flow and heat transfer characteristics using the momentum equation and the two-temperature non-equilibrium energy equation coupled with the enthalpy method to account for phase change in PCM. The effects of storage material, porosity and pore-diameter on the net useful energy that can be stored and released during a cycle, are studied. It is found that the first law efficiency of sensible heat storage system is less compared to LHTES. With the decrease in porosity, the first law and second law efficiencies of LHTES increase for both the charging and discharging period. There is no significant variation in energy and exergy efficiencies with the change in pore-diameter of the metal matrix.
\end{abstract}

Keyword: Latent heat thermal storage, PCM, Metal matrix, Second law, First law, Efficiency

* Corresponding author. Tel.: +91 22 25767392; fax: +91 2225726875.

E-mail address: sandip.saha@iitb.ac.in

(C) 2016. This manuscript version is made available under the Elsevier user license

http://www.elsevier.com/open-access/userlicense/1.0/ 


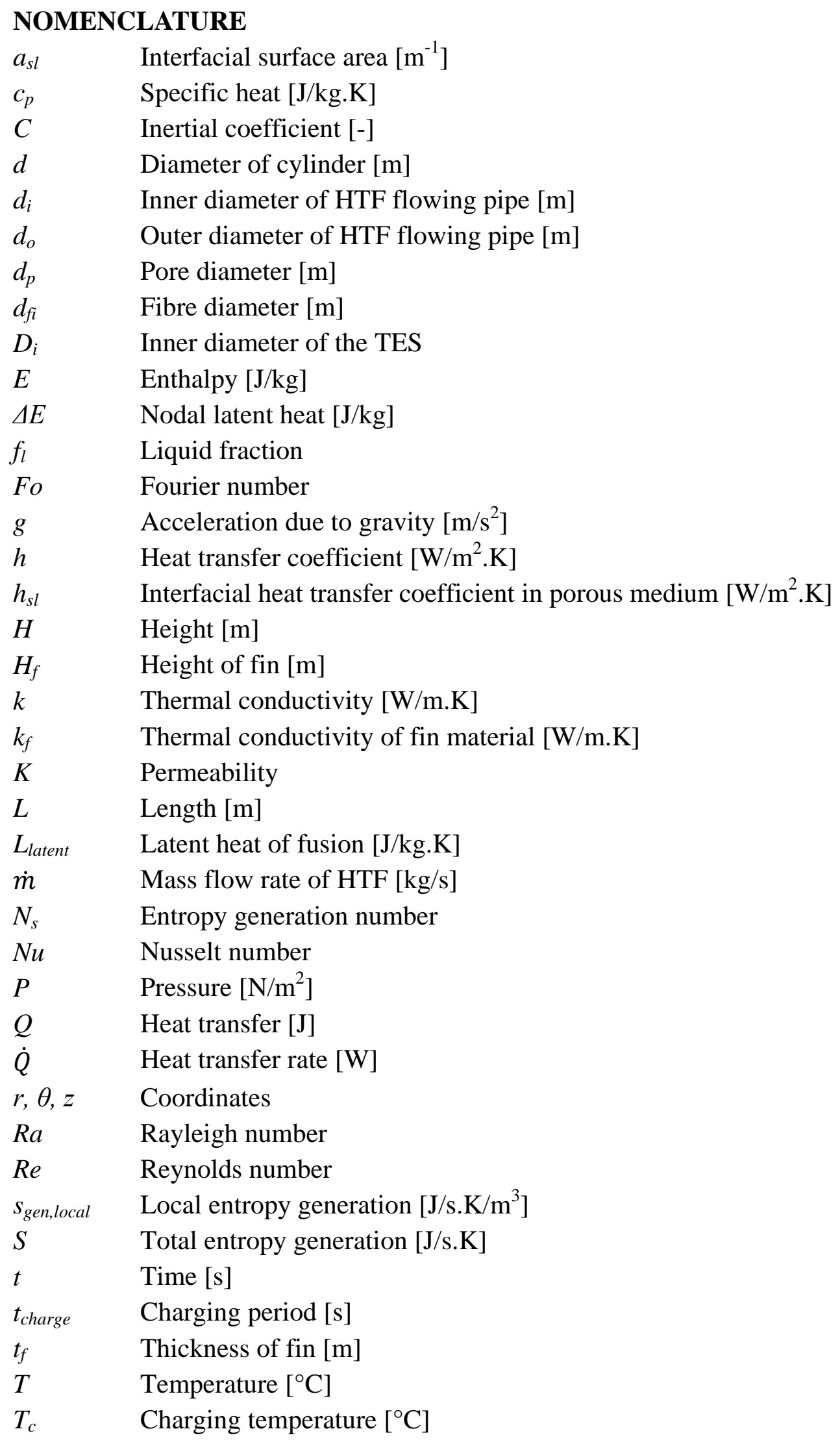


$T_{\text {critical }} \quad$ Critical temperature $\left[{ }^{\circ} \mathrm{C}\right]$

$T_{d} \quad$ Discharging temperature $\left[{ }^{\circ} \mathrm{C}\right]$

$T_{o} \quad$ Ambient temperature $\left[{ }^{\circ} \mathrm{C}\right]$

$T_{\text {sufface }} \quad$ Surface temperature of TES $\left[{ }^{\circ} \mathrm{C}\right]$

$\Delta T \quad$ Difference between maximum and minimum $\mathrm{HTF}$ outlet temperature in a cycle $\left[{ }^{\circ} \mathrm{C}\right]$

$u_{r}, u_{\theta}, u_{z} \quad$ Velocity component in $r, \theta$ and $z$ directions $[\mathrm{m} / \mathrm{s}]$

$\forall \quad$ Total volume of PCM $\left[\mathrm{m}^{3}\right]$

$X \quad$ Exergy [J/s.K]

\section{Greek symbol}

$\alpha \quad$ Thermal diffusivity $\left[\mathrm{m}^{2} / \mathrm{s}\right]$

$\beta \quad$ Thermal expansion coefficient $\left[\mathrm{K}^{-1}\right]$

$\eta \quad$ Efficiency

$\varepsilon \quad$ Porosity

$\mu \quad$ Dynamic viscosity $[\mathrm{kg} / \mathrm{m} . \mathrm{s}]$

$\rho \quad$ Density $\left[\mathrm{kg} / \mathrm{m}^{3}\right]$

$\Psi \quad$ Tortuosity

Subscripts

c Charging

d Discharging

eff Effective value

htf HTF

in Inlet

I First law

II Second law

$l \quad$ Liquid

$m \quad$ Melting point

$p \quad$ PCM

out Outlet

$s \quad$ Solid

total Total 


\section{INTRODUCTION}

Due to fast depletion of fossil fuels, solar radiation being a clean and renewable energy is an alternative attractive solution to energy crisis in recent years. Since the solar radiation fluctuates throughout the day, thermal energy storage (TES) can provide the required energy during the unavailability of solar radiation to produce electricity on continues basis. Thermal storage system stores energy when it in excess and discharges the same when it is needed later. Although the amount of energy required to be stored determine the size of storage system, a good storage system is that which can store large amount of energy in a relatively small space, thus energy storage per unit volume also plays a significant role. Traditionally, energy was stored in the form of sensible heat which requires large volume of storage material. The storage volume can be significantly reduced if energy is stored in the form of latent heat and thus can benefit practical applications enormously [1]. In this context, phase change material (PCM) can be used to store thermal energy in latent heat storage system (LHTES), as PCM possesses high latent heat of melting. PCMs are the substances which melt and solidify at almost constant temperature and also have the ability of absorbing and releasing sufficiently large amount of energy during phase change with low temperature difference.

Though PCMs have high energy density and nearly isothermal nature of storage process, its low thermal conductivity $(\sim 0.2-0.5 \mathrm{~W} / \mathrm{m} . \mathrm{K})$ and irreversibility during operation degrades the performance of the system. This thermal property often results in low charging and discharging rates, which will decrease the overall effectiveness of the system [2]. According to Tamme et al. [3], heat transfer from the surface can be enhanced by increasing heat transfer either on internal heat transfer surface or by exchanging heat storage medium. Sparrow et al. [4] reported that natural convection retards the solidification process and even can terminate the process. The retardation of the solidification process is a major deterrent to the heat transfer performance of 
thermal energy storage systems. This decreases the rate at which heat can be extracted from the PCM. Therefore, there is a need to enhance heat transfer during solidification. Several heat transfer enhancement techniques are available to augment heat transfer in PCM, such as insertion of metal matrix in the PCM [5-8], PCM-graphite composite [9], carbon fibres randomly packed in PCM [10-11], dispersion of metallic particles in PCM [12-13], multitube [14], encapsulated PCM [15-18], rings and bubble agitation in PCM [19] and addition of fins [20-23].

The most intensely analysed configuration, shell and tube heat exchanger is considered as LHTES in this paper as it is an effective PCM-based thermal energy storage system [24]. In this heat exchanger, PCM is packed in the shell side. As the thermal conductivity of PCM is low, metal matrix is used in this study as a thermal conductivity enhancer (TCE) that is inserted in the PCM. Mesalhy et al. [7] developed a numerical model to study the effect of adding a high thermal conductivity matrix on the performance of PCM-based TES. The heat transfer and melting rate of PCM in the TES were found to be augmented by inserting the porous matrix in PCM. Beckermann and Viskanta [25] investigated solid-liquid phase change experimentally and numerically in porous media considering natural convection in the molten region. Thermal equilibrium was assumed between PCM and solid matrix, however results were justified as the thermal conductivity of porous matrix in their case was low. Bejan [26] numerically studied the melting of PCM in porous media with local thermal equilibrium between solid matrix and PCM. It was found that the liquid Stefan number has a significant effect on melting rates and heat transfer. Heat transfer and melting/freezing rates of ice/water with metal matrix were analytically analysed by Tong et al. [5] assuming local thermal equilibrium. A notable enhancement of heat transfer were observed in presence of metal matrix. Whitaker [27] studied conduction heat transfer in porous matrix to determine the condition of local thermal equilibrium. Author 
suggested that a significant deviation from the local thermal equilibrium occurs due to large differences in physical properties of solid and liquid. Phanikumar and Mahajan [28] analysed high porosity matrix for natural and forced convection considering non-equilibrium between matrix and PCM. Two-energy equation was used and found significant deviation from the local thermal equilibrium model at high Rayleigh and Darcy number.

The assessment of performance and efficiency of LHTES systems is generally based on the first law of thermodynamics, which is used to identify the ways to improve the quantity of energy. Bejan [29] noted that the primary purpose of thermal energy storage system is to store useful work, which can be evaluated by the thermodynamic irreversibility analysis. Several literatures [30-31] are reported on the estimation of second law-based performance of thermal storage system. Ereck and Dincer [32] performed exergy analysis and calculated global entropy generation. Flucekiger and Garimella [34] investigated a cyclic operation of a molten-salt thermocline tank numerically and performed second-law analysis to estimate efficiency and performance of the system. Authors concluded that the presence of external convection introduces radial temperature gradients which leads to increased thermal diffusion causing entropy generation. Guelpa et al. [33] performed second law analysis on a shell and tube LHTES unit and investigated the design improvement of the system. Authors numerically solved solidification of finned and un-finned configurations and studied the time evolution of entropy generation. Modification of finned arrangement is suggested to improve the second law efficiency.

From a detailed literature review, it is found that various thermal performance enhancement techniques are studied extensively in order to increase heat transfer in PCM. As the energy efficiency is one of the major concerns, the thermal performance of metal matrix-based 
latent heat thermal storage system is evaluated mainly using the first law of thermodynamics. However, to quantify the useful energy during charging and discharging processes, a limited work is reported on the second law analysis of metal matrix-based latent heat thermal storage system. Therefore, there is a need for systematic and comprehensive study to identify the parameters which influence the local entropy generation in the thermal storage system. Accordingly, in this paper, the performance of thermal energy storage system (TES) using phase change material (PCM) is investigated based on the first and second law of thermodynamics for the medium temperature organic Rankine cycle (ORC) based concentrated solar power (CSP) plant $\left(200{ }^{\circ} \mathrm{C}\right)$ under fluctuating heat load. The parabolic trough based CSP plant is a two-loop system, comprising of primary and secondary loops as shown in figure 1. In the primary loop, Hytherm 600, which is a thermic oil, is selected as HTF. The TES is installed in the primary loop after the parabolic trough that is used to store and release energy during charging and discharging periods. Heat is transferred from the primary loop to the secondary loop through a heat exchanger placed after the TES. The secondary loop is a power generation cycle based on the organic Rankine cycle with a working fluid having critical temperature $\left(T_{\text {critical }}\right) \sim 200{ }^{\circ} \mathrm{C}$, such as R113 $\left(T_{\text {critical }}=214{ }^{\circ} \mathrm{C}\right), n$-haxane $\left(T_{\text {critical }}=234.7^{\circ} \mathrm{C}\right)$, isohaxane $\left(T_{\text {critical }}=224.6{ }^{\circ} \mathrm{C}\right)$, pentane $\left(T_{\text {critical }}=196.6{ }^{\circ} \mathrm{C}\right)[35]$.

A cycle comprising of charging and discharging period of $1800 \mathrm{~s}$ each is considered to represent fluctuations in the inlet temperature of HTF. A numerical model based on the twotemperature non-equilibrium energy equation coupled with the enthalpy technique taking into account of the phase change behaviour is developed for characterizing fluid flow and heat transfer in the LHTES. During charging and discharging period, the inlet temperature of HTF is taken as $\left(T_{\text {in }}\right) 200$ and $137.4{ }^{\circ} \mathrm{C}$, respectively. Based on the requirement of the HTF temperature 
to be maintained at $\sim 170{ }^{\circ} \mathrm{C}$, a commercial grade organic material A164 with melting temperature of $168.7^{\circ} \mathrm{C}$ is selected as a PCM. The heat transfer enhancement of PCM with metal matrix as a TCE in TES is evaluated and compared with the base case, which is, TES filled with PCM. The effects of porosity and pore diameter of metal matrix on the thermal performance of PCM-based TES are further investigated.

\section{DESCRIPTION OF PHYSICAL PROBLEM}

The latent heat storage system is a cylindrical shell and tube configuration, which consists of multiple tubes enclosed by a shell as shown in figure 2. Agyenim et al. [14] reported that the charging and discharging times are significantly faster in multi-tube concentric unit compared to that in single tube configuration due to increased convection and formation of multiple convective cells at tubes. In the present study, the HTF flows through the seven inner tubes and the PCM is kept in the annulus section. The inner and outer diameters of HTF tubes are chosen as 10.4 and $13.7 \mathrm{~mm}$, respectively. Hytherm 600 is used as the HTF and a commercial-grade organic material A164 is chosen as PCM. SS316 is used as the metal matrix and container materials to prevent any corrosion. The thermophysical properties of PCM, HTF and SS316 used in the numerical analyses are mentioned in table 1. The mass flow rate of HTF through a single tube is considered as $0.00285 \mathrm{~kg} / \mathrm{s}$ and the length of the LHTES is restricted to $800 \mathrm{~mm}$ based on the space constraint. The TES in this study mimics the lab-scale experimental setup developed in the laboratory. As the thermal conductivity of HTF is low $(0.116 \mathrm{~W} / \mathrm{m} . \mathrm{K})$, six longitudinal fins of dimensions 3.5 (height) $\times 1$ (thickness) $\times 800 \mathrm{~mm}$ are attached to the inner wall of each HTF tubes. The base case of LHTES without metal matrix is designed using steady state conduction heat transfer analysis based on the requirement of $286 \mathrm{~W}$ for half an hour of 
charging operation with the inlet and outlet HTF temperatures are assumed as 200 and $168.7^{\circ} \mathrm{C}$, respectively. To accommodate metal matrix embedded in PCM, the shell diameter of LHTES is taken as $100 \mathrm{~mm}$. One HTF tube is placed at the centre of LHTES and it is surrounded by another six tubes located equally distant (i.e. $60^{\circ}$ ) on the pitch circle diameter (PCD) of $66 \mathrm{~mm}$ to maintain equal quantity of PCM around the tubes.

In the numerical modelling, the metal matrix is modelled as porous medium. As twodimensional model of cross-section of LHTES is insufficient to capture the flow and heat transfer behaviour along the length, three-dimensional model is considered in the present numerical study. The LHTES can be symmetrically divided into six parts as the fluid flow and thermal behaviour of any symmetrical part can represent the complete configuration. The schematic diagram of the numerical domain is shown in figure 2(a) along with boundary conditions. The direction of gravity is chosen along the HTF flow through the tubes as shown in figure 2(b). The centrally located HTF tube is designated as HTF1 and another one, which is located at a distance from the HTF1 tube, is named as HTF2.

\section{MATHEMATICAL MODELING}

To model the PCM embedded in metal matrix as porous medium, volume-averaging technique is used. The enthalpy technique is employed to model the phase change and fluid flow in PCM [36]. Phase change is assumed to be isothermal. A few assumptions, such as laminar

and Newtonian flow and isotropic porosity are made [4] in the modeling. The expansion and shrinkage of PCM during phase change are neglected in the present model. There are large differences in thermal properties of PCM and metal matrix, hence a two-temperature energy equation model is adopted to solve heat transfer in PCM and metal matrix, considering local 
thermal non-equilibrium condition between PCM and metal matrix. The thermophysical properties of HTF, PCM, fins and metal matrix over a range of temperature are assumed to be constant and the change in volume during melting and solidification is neglected. The equivalent governing equations in the vector form using single-domain approach are given as,

a. Conservation of mass:

$$
\frac{\partial\left(\varepsilon \rho_{l}\right)}{\partial t}+\nabla \cdot\left(\rho_{l} u\right)=0
$$

b. Conservation of momentum:

$$
\frac{1}{\varepsilon} \frac{\partial\left(\rho_{l} u\right)}{\partial t}+\frac{1}{\varepsilon^{2}} \nabla \cdot\left(\rho_{l} u u\right)=-\nabla p+\nabla \cdot\left(\frac{\mu}{\varepsilon} \nabla u\right)+S_{i}
$$

c. PCM energy equation:

$$
\frac{\partial\left(\varepsilon \rho_{l} c_{p l} T_{l}\right)}{\partial t}+\nabla \cdot\left(\rho_{p} c_{p l} u T_{l}\right)=\nabla \cdot\left(k_{l, e f f} \nabla T_{l}\right)+S_{T l}
$$

d. Solid matrix energy equation:

$$
(1-\varepsilon) \frac{\partial\left(\rho_{s} c_{p s} T_{s}\right)}{\partial t}=\nabla \cdot\left(k_{s, e f f} \nabla T_{s}\right)+S_{T s}
$$

For cylindrical coordinate system, $u$ and $\nabla()$ and $\nabla .()$ are defined as follows:

$$
\begin{gathered}
u=u_{r} e_{r}+u_{\theta} e_{\theta}+u_{z} e_{z} \\
\nabla .()=\frac{1}{r} \frac{\partial}{\partial r}(r())+\frac{1}{r} \frac{\partial}{\partial \theta}()+\frac{\partial}{\partial z}(\quad) \\
\nabla()=e_{r} \frac{\partial}{\partial r}()+e_{\theta} \frac{\partial}{\partial \theta}()+e_{z} \frac{\partial}{\partial z}(\quad)
\end{gathered}
$$

The source terms $\left(S_{i}, S_{T l}\right.$ and $\left.S_{T s}\right)$ mentioned in the equations are listed in table 2. In table 2, $\Delta E$ in $S_{T l}$ is defined as,

$$
\begin{gathered}
\Delta E=0 \text { for } T<T_{\text {solidus }} \\
\Delta E=f_{l} L \text { for } T_{\text {solidus }} \geq T \geq T_{\text {liquidus }}
\end{gathered}
$$


For a pure material, isothermal phase change occurs, hence $T_{\text {solidus }}=T_{\text {liquidus }}=T_{m}$. When $f_{l}=1$, PCM is in fully liquid state and when $f_{l}=0$, PCM is in solid phase. For HTF flowing through the multiple tubes, the source terms $\left(S_{i}, S_{T l}\right)$ and porosity $(\varepsilon)$ are set to zero and 1, respectively and the thermophysical properties are taken for the HTF in equations 1-3. Heat transfer in fins attached to the inner diameter of HTF tubes and tube thickness are solved using equation 4 considering $\varepsilon=0$. To analyse TES filled with PCM, i.e. without metal matrix, the momentum equation (equation 2) is solved by taking $\varepsilon=1$ and $S_{z}=\rho g \beta\left(T_{l}-T_{m}\right.$ ), whereas in the PCM energy equation (equation 3 ), $S_{T l}$ is set to $-\frac{\partial(\rho \Delta E)}{d t}$.

The interfacial surface area $\left(a_{s l}\right)$ and the permeability of porous matrix $(K)$ in table 2 are determined by taking the following relations given by Fourier and Du Plesis [37].

$$
\begin{gathered}
a_{s l}=\frac{3}{d}(3-\psi)(\psi-1) \\
K=\frac{\varepsilon^{2} d^{2}}{36(\psi-1) \psi}
\end{gathered}
$$

The relation between $d$ and $d_{p}$ can be written as,

$$
\frac{d_{p}}{d}=\frac{3-\psi}{\psi}
$$

The tortuosity $(\psi)$ in equation 9 can be obtained as [37],

$$
\psi=2+2 \cos \left[\frac{4 \pi}{3}+\frac{1}{3} \cos ^{-1}(2 \varepsilon-1)\right]
$$

The drag coefficient $\left(C_{D, l}\right)$ is found by the following expression [37],

$$
C_{D, l}=1+\frac{10}{R e^{0.667}}
$$

where

$$
R e=\frac{\rho U d}{\mu}
$$

The inertial coefficient $(C)$ in table 2 can be obtained as [31], 


$$
C=(3-\psi)(\psi-1) \frac{C_{D, l} \psi^{1.5}}{24 \varepsilon^{2}}
$$

The effective thermal conductivity $\left(k_{e f f}\right)$ of high porosity porous medium can be determined by [7],

$$
k_{e f f}=\frac{\left[k_{p}+\pi\left(\sqrt{\frac{1-\varepsilon}{3 \pi}}-\frac{1-\varepsilon}{3 \pi}\right)\left(k_{s}-k_{p}\right)\right]\left[k_{p}+\frac{1-\varepsilon}{3}\left(k_{s}-k_{p}\right)\right]}{k_{p}+\left[\frac{4}{3} \sqrt{\frac{1-\varepsilon}{3 \pi}}(1-\varepsilon)+\pi \sqrt{\frac{1-\varepsilon}{3 \pi}}-(1-\varepsilon)\right]\left(k_{s}-k_{p}\right)}
$$

The $k_{l, e f f}$ and $k_{s, e f f}$ in equations 3 and 4 are obtained by setting $k_{s}$ and $k_{p}$ equal to zero, respectively. The density, specific heat and latent heat of the porous medium are calculated by the volume-averaging technique [7] as,

$$
\begin{gathered}
\rho_{e f f}=(1-\varepsilon) \rho_{s}+\varepsilon \rho_{p} \\
(\rho c)_{e f f}=(1-\varepsilon) \rho_{s} c_{s}+\varepsilon \rho_{p} c_{p} \\
L_{\text {latent }, \text { eff }}=\varepsilon L_{\text {latent }}
\end{gathered}
$$

The interfacial heat transfer coefficient $\left(h_{s l}\right)$ between the PCM and the metal matrix is determined by assuming quasi-steady heat conduction between the porous matrix and the PCM where motion of liquid phase is neglected [7]. The Nusselt number is defined as,

$$
N u=\frac{h_{s l} d_{f i}}{k_{p}}=\frac{2\left(\frac{k_{s}}{k_{p}}\right)}{\ln (1-B)+\left(\frac{k_{s}}{k_{p}}\right) \ln (1+A)}
$$

For small values of $A$ and $B$, the relation between $A$ and $B$ is found as [7],

$$
A=B \sqrt{\frac{\alpha_{s}}{\alpha_{p}}}
$$

\section{a. Energy Efficiency}


To quantify the effectiveness of LHTES in storing and releasing energy, the efficiency of LHTES is calculated for charging, discharging period based on the first law of thermodynamics. The charging efficiency can be expressed as,

$$
\eta_{c}=\frac{Q_{i n, c}-Q_{o u t, c}}{Q_{t o t a l}}
$$

While the discharging efficiency can be written as,

$$
\eta_{d}=\frac{Q_{o u t, d}-Q_{i n, d}}{Q_{\text {total }}}
$$

The total storage capacity $\left(Q_{\text {total }}\right)$ for the symmetric part is taken as $85797 \mathrm{~J}$. The overall efficiency of LHTES can be obtained as,

$$
\eta_{I, o}=\eta_{c} \eta_{d}
$$

\section{b. Entropy generation analysis}

Entropy is the measure of irreversibility as any irreversible process is accompanied by increase in entropy generation. When the equilibrium between system and surrounding is reached, the entropy generation attains it maximum value. Also with increase in entropy, exergy of system degrades, thus entropy generation of a system needs to be calculated to estimate the irreversibility of the LHTES system. Assuming isothermal phase change, the local entropy generation can be calculated as,

$$
s_{\text {gen,local }}=\frac{k(\nabla \mathrm{T})^{2}}{T^{2}}
$$

Total entropy generation $(S)$ can be subsequently obtained as,

$$
S=\int s_{g e n, l o c a l} d \forall
$$

where $\forall$ is volume of the domain. The exergy input $\left(X_{i n}\right)$ for charging and discharging processes can be expressed as, 


$$
\begin{gathered}
X_{i n, c}=\dot{m} c_{p, h t f}\left[\left(T_{i n}-T_{0}\right)-T_{0} \ln \left(\frac{T_{i n}}{T_{0}}\right)\right. \\
X_{\text {in,d }}=\dot{m} c_{p, h t f}\left[\left(T_{P C M}-T_{i n}\right)\left(1-\frac{T_{0}}{T_{P C M}}\right)\right.
\end{gathered}
$$

where $T_{0}$ is taken as the ambient temperature of $30{ }^{\circ} \mathrm{C}$.

\section{c. Entropy generation number and Second law efficiency:}

Entropy generation number $\left(N_{s}\right)$ can be defined as the ratio of exergy destroyed or anergy to the input exergy and is expressed as,

$$
N_{s}=\left(\frac{\dot{m} T_{0} S}{X_{\text {in }}}\right)
$$

The second law efficiency is the amount of useful energy to the maximum possible energy that can be used and is calculated as,

$$
\eta_{I I}=\left(1-N_{s}\right)
$$

\section{d. Boundary and initial conditions}

At $\mathrm{t}=0, T(r, \theta, z, 0)=168.6^{\circ} \mathrm{C}$ which is slightly below $\mathrm{T}_{m}$ in order to reduce sensible heating. The boundary conditions are,

i) No slip and impermeability condition at the walls, i.e. $u=0$.

ii) At inlet, $z=0, u_{z}=u_{\text {in }}$ and $T_{z}=T_{\text {in }}$

iii) At outlet, $z=L$, pressure outlet boundary condition i.e. $P=0$.

iv) Insulated sidewalls and outer surface of the TES at $r=\frac{D_{i}}{2}$.

v) Symmetric boundary conditions are taken for the symmetry planes at $\theta=0$ and $\theta=60^{\circ}$.

The inlet temperature $\left(T_{i n}\right)$ of HTF is maintained at $200{ }^{\circ} \mathrm{C}$ for $1800 \mathrm{~s}$ during charging period and at $137.4{ }^{\circ} \mathrm{C}$ during discharging period for the same duration. The governing equations are solved iteratively using finite volume method (FVM) according to the SIMPLE algorithm. A 
commercial software Fluent 14 [38] is used in the simulations. The coefficients in the momentum and energy equations are determined by the power law. Convergence of momentum equation is taken as $10^{-3}$, while for solving the energy equation, it is chosen as $10^{-6}$.

\section{e. Model verification}

The present numerical model is validated by comparing it with the results reported by Khillarkar et al. [39] who simulated the melting of PCM in an irregular geometry. In their study, a finite element computational study was performed for a free convection dominated melting of a pure phase change material, which is kept in concentric horizontal annuli. The configuration of their geometry is a square external tube with a circular tube inside it. The inner cylinder wall is subjected to uniform temperature higher than the melting temperature of the PCM and the outer wall is adiabatic. $n$-Octadecane was used as the PCM. The initial temperature and hot wall temperature were considered as $27{ }^{\circ} \mathrm{C}$ and $43{ }^{\circ} \mathrm{C}$. The non-dimensional domain used in the present study is taken as $1(x / d) \times 2(y / d)$ with diameter of the cylinder, $d=1 \mathrm{~mm}$. For Fourier number $(F o)=0.1296$ (corresponding to $360 \mathrm{~s}$ ) and $R a=2.844 \times 10^{6}$, the solid liquid interface reported by Khillarkar et al. [39] and the present numerical model is shown in figure 3(a). As evident from the streamlines plot in figure 3(b), two convection cells are formed and the PCM is melted more at top of the heated wall of the inner cylinder due to upward rise of melt front along the heated cylinder. There exists a good agreement between the location of solid-liquid interface and the streamlines predicted by Khillarkar et al. [39] and the present model.

\section{f. Grid independence study}

The grid independence study is performed to identify the appropriate grid size to be used in the numerical simulation. In this study, three grid sizes are taken viz. (i) coarse grid, (ii) fine grid and (iii) finer grid keeping the time step $(\Delta t)$ constant at $0.1 \mathrm{~s}$. The total number of cells in 
the domain is 544047 for the fine grid case. In other two cases, the number of control volumes is changed by a constant factor of 1.5 times compared to the fine grid. The outlet temperature of HTF flowing through the centre pipe (HTF 1) is plotted with time for the three cases during charging period in figure 5 . It can be noted that the temperature difference $(\Delta T)$ between coarse and fine grids is much higher (maximum $1.6^{\circ} \mathrm{C}$ ) compared to that between fine and finer grids (maximum $0.27^{\circ} \mathrm{C}$ ). Hence the fine grid size is chosen for the further simulations.

\section{RESULT AND DISCUSSIONS}

\section{a. Comparison of latent heat and sensible heat storage system}

The thermal performance of LHTES containing phase change material (PCM) is evaluated numerically by solving the governing equations (equation 1-4) along with initial and boundary conditions. The initial temperature of the storage system is chosen as $168.6^{\circ} \mathrm{C}$, which is slightly lower than the melting temperature of the PCM, i.e. $T_{m}=168.7^{\circ} \mathrm{C}$. The outer walls of the storage system are kept insulated, which corresponds to a conservative design. The charging and discharging periods are considered as $1800 \mathrm{~s}$ each, and the corresponding inlet temperature of HTF is maintained at 200 and $137.4^{\circ} \mathrm{C}$, respectively.

To evaluate the efficacy of latent heat thermal storage in reducing fluctuations in the incoming HTF temperature, it is compared to a sensible heat thermal storage (SHTES) filled with stainless steel. The momentum equation (equation 2) and the latent heat content in the energy equation (equation 4) for steel are set to zero. Figure 5(a) shows the average temperature of PCM and steel as storage media in the thermal energy storage system for a cycle. In both the cases, PCM and steel temperatures increase from the initial temperature as heat is transferred from HTF to the storage material during the charging period. As PCM starts melting and absorbs 
heat as latent heat, the rise in PCM temperature is less compared to that of steel. The temperature of steel reaches to $198.6{ }^{\circ} \mathrm{C}$ at $1800 \mathrm{~s}$, whereas the same for $\mathrm{PCM}$ is $189.1{ }^{\circ} \mathrm{C}$. During the discharging period, the average temperature of PCM decreases for initial $40 \mathrm{~s}$, whereas the average temperature of steel decreases monotonically. The rate of decrease in temperature for PCM is lower than that for steel as the thermal diffusivity of steel is higher than that of PCM. Once PCM reaches its melting temperature, the temperature of PCM decreases gradually. This effect can be observed on the outlet temperature of HTF1 and HTF2 as shown in figure 5(a) for both charging and discharging processes. It can be observed that the outlet temperature of HTF, which increases from the initial temperature, becomes stable after $60 \mathrm{~s}$ when the melting of PCM starts in LHTES. There is small difference in the outlet temperatures of HTF passing through the centre tube and the surrounding tubes. The difference is due to the arrangement of tubes, as the centre tube is surrounded by the PCM and six outer tubes that affect heat transfer. Hence the outlet temperature of HTF in the centre pipe is slightly higher compared to that of HTF in the surrounding tubes during the charging period, whereas the opposite trend is observed during the discharging process. The maximum difference in outlet temperature of HTF between centre and outer tubes is found to be $2.2{ }^{\circ} \mathrm{C}$ in a cycle. Therefore, in further analyses, the average outlet temperature of HTF in the centre tube (HTF1) is plotted. During the discharging period, PCM releases heat to the HTF, as HTF is at lower temperature. The HTF outlet temperature starts to drop after the commencement of the discharging period to $169^{\circ} \mathrm{C}$ at $1820 \mathrm{~s}$. Subsequently, the HTF outlet temperature reduces gradually for the remaining period of the discharging process and reaches $145.9^{\circ} \mathrm{C}$ at $3600 \mathrm{~s}$. In case of steel as storage medium in SHTES, the HTF outlet temperature increases monotonically as compared to PCM during the charging period. At the end of the charging period, the outlet temperature of $\mathrm{HTF}$ is $198.6{ }^{\circ} \mathrm{C}$ and the same is found to be 
$139.9{ }^{\circ} \mathrm{C}$ after the discharging period. It can be noted that there is no stabilization period in case of SHTES. The fluctuation in outlet temperature of HTF after charging and discharging processes $(\Delta T)$ is $43.3^{\circ} \mathrm{C}$ for PCM and $58.7{ }^{\circ} \mathrm{C}$ for steel. The overall energy efficiency $\left(\eta_{I, o}\right)$ of storage system with PCM is found to be $7.3 \%$, which is more than that of SHTES $\left(\eta_{I, o}=5.7 \%\right)$.

Figure 6 shows the temperature contours at a cross-section located midway of the LHTES, i.e. $z=0.4 \mathrm{~m}$ for PCM and steel as storage materials after $1800 \mathrm{~s}$ and $3600 \mathrm{~s}$. It can be observed that the temperature of steel in TES remains almost constant due to its high thermal conductivity. The melting and solidification of PCM initiate from the outer surface of HTF tubes (figure 6(a) and (b)) and there is a variation in temperature in case of PCM as its thermal conductivity is low, which causes thermal stratification (figure 6(a)) in PCM. Hence it can be concluded that the temperature gradient is more for PCM as compared to steel.

The time evolution entropy generation and exergy input of the storage system filled with PCM and steel are shown in figure 5(b). It can be observed that at the initial period of charging process, the volumetric entropy generation increases due to the high temperature gradient and low temperature of the storage material. After $100 \mathrm{~s}$, the temporal change of volumetric entropy generation starts decreasing gradually due to the reduction in temperature gradient and the increase in temperature of storage material. However the entropy generation in PCM is higher compared to that of steel, as more uniform temperature distribution exists in steel. During the initial period of discharging process, there is an increase in entropy generation for $40 \mathrm{~s}$ for PCM and steel due to the higher temperature gradient caused by the low inlet HTF temperature. As time progresses, the entropy generation decreases because of the decrease in local temperature gradient due to relatively more uniform temperature distribution in the storage. However, after $2000 \mathrm{~s}$ in case of PCM as the storage medium, the temperature gradient between solid and liquid 
phase increases as a result of phase change of PCM. Afterwards, once the PCM solidifies completely, a drop in entropy generation is observed, which can also be noticed in case of steel after $1840 \mathrm{~s}$. It can be observed from figure 5(b) that the exergy input $\left(X_{\text {in }}\right)$ remains constant during the charging period for both the storage materials, as it depends on the HTF inlet temperature and ambient temperature, which are constant at 200 and $30{ }^{\circ} \mathrm{C}$, respectively (equation 25). During the discharging process, the exergy input for both the PCM and steel reduces due to the decrease in temperature of storage material (equation 26). However, the exergy input of PCM becomes stable after $100 \mathrm{~s}$ when it reaches the melting temperature.

The second law efficiency is calculated using equation 28 and is shown in figure 5(c) for PCM and steel as storage material. The average charging and discharging exergy efficiencies of steel are found to be $99 \%$ and $97 \%$, respectively and the corresponding values are $96.1 \%$ and 82.3\% for PCM. Although the average exergy efficiency of steel shows higher value for charging and discharging processes as compared to PCM, the net amount of useful stored and extracted energy in case of PCM is higher. Thus LHTES is better than SHTES in stabilizing the temperature fluctuations of the incoming HTF.

\section{b. Effect of TCE}

Metal matrix is used as the thermal conductivity enhancer (TCE) to augment heat transfer in PCM. The amount of TCE added in PCM determines the porosity of storage system. An addition of $3 \%$ of TCE in PCM corresponds to the porosity $(\varepsilon)$ of 0.97 , which leads to the effective thermal conductivity enhancement that subsequently increases heat tranfer. In this study, the pore diameter is kept constant at $1 \mathrm{~mm}$. The temporal variation of HTF outlet temperature during charging and discharging period for LHTES with $\varepsilon=0.97$ is shown in figure

7. The fluctuation in HTF outlet temperature $(\Delta T)$ reduces $\left(42.4^{\circ} \mathrm{C}\right)$ with addition of metal 
matrix compared to that for TES filled with PCM $\left(43.3^{\circ} \mathrm{C}\right)$. To investigate the effect of addition of TCE on the enhancement of heat transfer in PCM, three more porosities, viz. $\varepsilon=0.95,0.9$, 0.85 are studied and is shown in figure 7. It can be observed that the HTF outlet temperature stabilizes at a lower temperature during melting of PCM with the addition of metal matrix to PCM. After the completion of melting of PCM, the HTF outlet temperature rises and it occurs earlier with the decrease in porosity of LHTES due to the reduction in latent heat capacity of the storage. It is found that the temperature fluctuation after charging and discharging processes $(\Delta T)$ for $\varepsilon=0.95,0.9$ and 0.85 is $41.4,40.6$ and $42{ }^{\circ} \mathrm{C}$, respectively. Hence it can be concluded that the fluctuation in HTF outlet temperature in a cycle reduces with the addition of TCE and the minimum fluctuation is obtained for $\varepsilon=0.9$ in the present study.

Figure 8 shows the comparison of charging, discharging and overall energy efficiencies for different porosities. It can be noted that the charging efficiency from the first law of thermodynamics for $\varepsilon=0.97,0.95,0.9$ and 0.85 is $27.6 \%, 28.4 \%, 30.1 \%$ and $30.7 \%$, respectively, whereas the corresponding discharging efficiency is $28.3 \%, 29.5 \%, 32.2 \%$ and $34 \%$. With the decrease in porosity, the energy efficiency for charging and discharging increases, which collectively increases the overall efficiency. The increase in energy efficiency is due to the augmentation of heat transfer because of enhancement in the effective thermal conductivity of PCM.

The time evolution of second law efficiency and entropy generation are calculated for different porosities, viz. $\varepsilon=0.97,0.95,0.9$ and 0.85 . Figure 9 shows the volumetric entropy generation for different porosities with time during charging and discharging period. It can be observed that the volumetric entropy generation is lowest in case of $\varepsilon=0.85$. Entropy generation is directly related to the irreversibilty of the system. As heat transfer in PCM increases with 
addition of metal matrix, the avialabilty of energy increases, which results in the decrease in irreversibilty for $\varepsilon=0.85$.

The temporal variation of exergy efficency $\left(\eta_{I I}\right)$ is shown in figure 10 for different porosities. The second law efficiency provides the estimation of useful part of energy, which is calculated from the first law of thermodynamics. It can be observed from the figure that the exergy efficiency during charging period for $\varepsilon=0.85$ is highest due to less temperature gradient in the LHTES because of the presence of higher percentage of metal matrix. During the discharging process, it is found that the second law efficiency decreases with time at a faster rate for higher porosity as campared to lower porosity i.e. $\varepsilon=0.85$. The second law efficiency for $\varepsilon=$ 0.85 with time remains almost constant and it is higher than that for other porosities. For $\varepsilon=$ 0.97, 0.95, 0.9 and PCM, it is observed that there is an increase in exergy efficiency after $3500 \mathrm{~s}$, which is due to complete solidification of PCM, that results in the decrease in entropy generation.

Figure 11 shows the average second law efficiency of LHTES with different porosities. The average second law efficiency $\left(\eta_{I I}\right)$ of charging after $1800 \mathrm{~s}$ for $\varepsilon=0.97,0.95,0.9,0.85$ is $96.9 \%, 97.1 \%, 97.7 \%$ and $97.9 \%$, whereas for the discharging period, it is $82.3 \%, 87.8 \%, 90.5 \%$ and $91.5 \%$, respectively. During charging and discharging processes, the average exergy efficiency is highest for the lowest porosity (i.e. $\varepsilon=0.85$ ) studied. The average second law efficiency during charging is higher, which indicates exergy transfer from the HTF to PCM is efficient in charging compared to discharging where the transfer of stored energy is from PCM to HTF. This can be attributed to melt convection that enhances heat transfer during melting of PCM compared to conduction, which is the dominant mode of heat transfer while PCM is 
undergoing solidification. Hence it can be concluded that the addition of a small amount of metal matrix can increase heat transfer and thermal performance of LHTES.

\section{c. Effect of pore diameter $\left(d_{p}\right)$}

The maximum first and second law efficiencies are found at the porosity of 0.85 with pore diameter $\left(d_{p}\right)$ of $1 \mathrm{~mm}$. Hence the effect of pore diamter on the thermal behaviour of LHTES is investigated by varying the pore diameter as $0.33,0.5,2$ and 3 , at a fixed porosity of 0.85 keeping the LHTES volume constant. The temperature histories of HTF at outlet for different pore diameter $\left(d_{p}\right)$ of $0.33,0.5,1,2$ and $3 \mathrm{~mm}$ are shown in figure 12 . Accordingly, the corresponding characteristic lengths for the cell $(d)$ are $0.3,0.4,0.9,1.9,2.9 \mathrm{~mm}$ for a given porosity of $\varepsilon=0.85$. It can be observed that the variation in average HTF outlet temperature with time is not significantly affected by the pore diameter. The maximum temperature deviation in HTF outlet temperature in a cycle for different pore diameters is $\sim 2.1^{\circ} \mathrm{C}$, considering $d_{p}=1 \mathrm{~mm}$ as the reference. With the varying pore diameter, the interficial heat transfer cofficient and heat transfer area change, however the effective thermal conductivity of PCM remains the same. The interficial heat transfer cofficient and heat transfer area insignificantly affect the vatiation in HTF outlet temperature due to the multiplier $\left(T_{s}-T_{l}\right)$ in equation 3 . The first law efficiency is calculated for different pore diameters for charging and discharging period and is shown in figure 13. It can be noted that there is no significant difference in the first law efficiency. The average overall efficiency for all cases is $10.4 \%$ with a maximum deviation of $0.3 \%$.

The thermal performance based on the second law of thermodynamics is also evaluated for different pore diameters of $0.33,0.5,1,2$ and $3 \mathrm{~mm}$. Figure 14 shows the volumteric entropy generation in LHTES for different pore diameters with time. The volumetric entropy generation is found to be lowest for the case of $d_{p}=0.33 \mathrm{~mm}$ and it is observed to be increasing with the 
increase in pore diameter for a fixed porosity of 0.85 . The evaluation of second law efficeincy with time is calculated based on the volumertric entropy generation for charging and discharging period and is shown in figure 15 . The second law efficiency with time sighlty varies with pore diameter and it is found that the exergy efficiency is lowest for the smallest pore diameter studied (i.e. $d_{p}=0.33 \mathrm{~mm}$ ) during charging and discharging period. Figure 16 shows the average second law efficiency of LHTES with different porosities. The average second law efficiency after charging for $d_{p}=0.33,0.5,1,2$ and $3 \mathrm{~mm}$ is $98.5 \%, 98.5 \%, 97.9 \%, 97.9 \%, 97.8 \%$, respectively and for the discharging period, it is $92.6 \%, 92.4 \%, 91.8 \%, 90.9 \%$ and $90 \%$. Hence, it can be noted that the variation in second law efficiency with change in pore diameter is low. The second law efficiency of LHTES is affected by the temperature gradient and nodal temperature (equations 23 and 28), as the effective thermal conductivity of PCM is independent on the pore diameter (equation 14). However, the change in nodal temperature and temperature gradient is small with the variation in pore diameter, as these two parameters are not significantly affected by the interficial heat transfer cofficient $\left(h_{s l}\right)$ and heat transfer area $\left(a_{s l}\right)$. This is evident from the temperature contour at the cross sectional plane located midway of the LHTES (i.e. $z=$ $0.4 \mathrm{~m}$ ) at the end of charging and discharging period for two pore diameters of 0.33 and $3 \mathrm{~mm}$, as shown in figure 17.

\section{CONCLUSIONS}

The thermal performance of thermal energy storage (TES) system using PCM is investigated for the medium temperature application $\left(\sim 170{ }^{\circ} \mathrm{C}\right)$ such as ORC based solar thermal power plant. Metal matrix is used as the thermal conductivity enhancers (TCE). A numerical model using enthalpy technique is employed to characterize the thermal storage system based on 
the first and second law of thermodynamics. The fluctuations in the inlet temperature of HTF are introduced by a cycle consisting of charging and discharging period. The heat transfer enhancement of PCM with TCE in TES is also evaluated and compared with TES filled with PCM. The effect of porosity of metal matrix on the thermal performance of PCM-based TES is investigated. It is found that PCM can be used in more effective way compared to the sensible heat storage system. Addition of TCE in PCM improves the temperature distribution in PCM, which enhances the heat transfer rate in PCM due to augmentation in the effective thermal conductivity of PCM. The reduction in fluctuation in HTF temperature is significantly affected by the change in porosity. The charging, discharging and overall efficiency are found to increase with decreasing porosity and the lowest value is obtained for porosity of 0.85 for a given pore diameter which can be attributed to maximum thermal diffusivity compared to other porosities considered in this study. The time evolution second law analysis is evaluated for different porosities to calculate the useful energy and it is found that energy can be extracted more efficiently at low porosity, as entropy generation is found minimum for porosity of 0.85 . Further the effect of pore diameter is studied on the performance of storage system. The reduction in HTF temperature fluctuation is not significantly affected by varying pore diameter. Similarly, the effect on first law and second law efficiencies due to the variation in pore diameter is found to be marginal. The present study can be extended to analyse the thermal performance of large scale industrial model. The dynamic performance of the large scale industrial model could be different from that of the present system, due to scale of the system and the external heat transfer depending on the surface area.

\section{ACKNOWLEDGEMENTS}


This paper is based on work supported in part under the US-India Partnership to Advance Clean Energy-Research (PACE-R) for the Solar Energy Research Institute for India and the United States (SERIIUS), funded jointly by the U.S. Department of Energy under Subcontract DE-AC36-08GO28308 to the National Renewable Energy Laboratory and the Government of India, through the Department of Science and Technology under Subcontract IUSSTF/JCERDCSERIIUS/2012 dated $22^{\text {nd }}$ Nov. 2012.

\section{REFERENCES}

1. S.P. Sukhatme, J.K. Nayak, Solar energy- principles of thermal collection and storage, third ed., Tata McGraw Hill Education Private Limited, New Delhi, India, 2008.

2. F. Agyenim, N. Hewitt, P. Eames, M. Smyth, A review of materials, heat transfer and phase change problem formulation for latent heat thermal energy storage systems (LHTESS), Renewable and Sustainable Energy Reviews 14 (2010) 615-628.

3. R. Tamme, D. Laing, W.D. Steinmann,S. Zunft, Innovative thermal energy storage technology for parabolic trough concentrating solar power plants, in Proc. 4th ISES Eur. Solar Congr., Bologna, Italy, 2002.

4. E.M. Sparrow, E.D. Larson, J.W. Ramsey, Freezing on a finned tube for either conductioncontrolled or natural-convection-controlled heat transfer, Int. J. Heat Mass Transfer 24 (1981) 273-284.

5. X. Tong, J.A. Khan, M.R. Amin, Enhancement of heat transfer by inserting a metal matrix into a phase change material, Numer. Heat Transfer 30 (1996) 125-141.

6. X.Py, R. Olives, S. Mauran, Paraffin/porous-graphite-matrix composite as a high and constant power thermal storage material, Int.J. Heat and Mass Transfer 44 (2001) 27272737.

7. O. Mesalhy, K. Lafdi, A. Elgafy, K. Bowman, Numerical study for enhancing the thermal conductivity of phase change material (PCM) storage using high thermal conductivity porous matrix, Energy conservation and Management. 46 (2005) 847-867.

8. Z.G. Wu, C.Y. Zhao, Experimental investigations of porous materials in high temperature thermal energy storage systems. Solar Energy 85 (2011) 1371-1380.

9. J. Zhang, X. Zhang, Y. Wan, D. Mei, B. Zhang, Preparation and thermal energy properties of paraffin/halloysite nanotube composite as form-stable phase change material, Solar Energy 86 (2012) 1142-1148.

10. J. Fukai, M. Kanou, Y. Kodama, O. Miyatake, Thermal conductivity enhancement of energy storage media using carbon fibers, Energy Conversion and Management 41 (2000) $1543-1556$. 
11. Y. Hamada, W. Ohtsu, J. Fukai, Thermal response in thermal energy storage material around heat transfer tubes: effect of additives on heat transfer rates, Solar Energy 75 (2003) 317-328.

12. R. Sigel, Solidification of low conductivity material containing dispersed high conductivity particles, International Journal of Heat and Mass Transfer 20 (1977) 1087-1089.

13. E.S. Mettawee, G.M.R. Assassa, Thermal conductivity enhancement in a latent heat storage system, Solar Energy 81 (2007) 839-845.

14. F. Agyenim, P. Eames, M. Smyth, Heat transfer enhancement in medium temperature thermal energy storage system using a multitube heat transfer array, Renewable Energy 35(1) (2010) 198-207.

15. M.N.A. Hawlader, M.S. Uddin, M.M. Khin, Microencapsulated PCM thermal energy storage system, Applied Energy 74 (2003) 195-202.

16. F. Regin, S.C. Solanki, J.S. Saini, An analysis of a packed bed latent heat thermal energy storage system using PCM capsules: numerical investigation, Applied Energy 34 (2009) 1765-1773.

17. W. Zhao, S. Neti, A. Oztekin, Heat transfer analysis of encapsulated phase change materials, Applied Thermal Engineering 50 (2013) 143-151.

18. K. Nithyanandam, R. Pitchumani, A. Mathur, Analysis of a latent thermocline storage system with encapsulated phase change materials for concentrating solar power, Applied Energy 113 (2014) 1446-1460.

19. R. Velraj, R.V. Seeniraj, B. Hafner, C. Faber, K. Schwarzer, Heat transfer enhancement in a latent heat storage system, Solar Energy 65 (1999) 171-180.

20. K. Sasaguchi, H. Takeo, Effect of the orientation of a finned surface on the melting of frozen porous media. Int. J. of Heat and Mass Transfer 37 (1994) 13-26.

21. K.A.R. Ismail, C.L.F. Alves, M.S. Modesto, Numerical and experimental study on the solidification of PCM around a vertical axially finned isothermal cylinder, Applied Thermal Engineering 21 (2001) 53-77.

22. Z. Liu, X. Sun, C. Ma, Experimental investigations on the characteristics of melting processes of stearic acid in an annulus and its thermal conductivity enhancement by fins, Energy Conversion and Management 46 (2005) 959-969.

23. K. Ermis, A. Erek, I. Dincer, Heat transfer analysis of phase change process in a finnedtube thermal energy storage system using artificial neural network, International Journal of Heat and Mass Transfer 50 (2007) 3163-3175.

24. Y. Zhang, A. Faghri, Heat transfer enhancement in latent heat thermal energy storage system by using the internally finned tube, International Journal of Heat and Mass Transfer 39(1996) 3165-3173.

25. C. Beckermann, R. Viskanta, Natural convection solid/liquid phase change in porous media, International Journal of Heat and Mass Transfer 31 (1988) 35-46.

26. A. Bejan, Theory of melting with natural convection in an enclosed porous media, J. Heat Transfer, ASME 111 (1989) 407-415. 
27. S. Whitaker, The method of volume averaging, Kluwer Academic Publishers, Norwell, MA, USA (1999).

28. M. Phanikumar, R. Mahajan, Non-Darcy natural convection in high porosity metal foams, International Journal of Heat and Mass Transfer, 45 (2002) 3781-3793.

29. A. Bejan, Two thermodynamic optima in design of sensible heat units for energy storage, International Journal of Heat and Mass Transfer 100 (1978) 708-712.

30. H.J. Xu, C.Y. Zhao, Thermal efficiency analysis of a cascaded latent heat/cold storage with multi-stage heat engine model, Renewable Energy, 86 (2016) 228-237.

31. D. Aydin, Z. Ultu, O. Kincay, Thermal performance analysis of a solar energy sourced latent heat storage, Renewable and Sustainable Energy reviews, 50 (2015) 1213-1225.

32. A. Eric, I. Dincer, A new approach to energy and exergy analyses of latent heat storage unit, Heat Transfer Engineering 30 (2009) 506.

33. E. Guelpa, A. Sciacovelli, V. Vittorio, Entropy generation analysis for design improvement of a latent heat storage system, Energy 53 (2013) 128-138.

34. S.M. Flueckiger, S.V. Garimella, Second-law analysis of molten salt thermal energy storage in thermoclines, Solar energy 86 (2012) 1621-1631.

35. N.B. Desai, S. Bandyopadhyay, Thermo-economic analysis and selection of working fluid for solar organic Rankine cycle, Applied Thermal Engineering 95 (2016) 471-481.

36. D. Brent, V.R. Voller, K.J. Reid, Enthalpy-porosity technique for modelling convectiondiffusion phase change: application to the melting of a pure metal, Numerical Heat Transfer 13 (1988) 297-318.

37. J. G. Fourie, J. P. Du Plessis, Pressure drop modelling in cellular metallic foams, Chemical Engineering Science 57 (2002) $2781-2789$.

38. FLUENT Manual, ANSYS/FLUENT Release Version 14. ANSYS Inc., Documentation, 2012.

39. D.B. Khillarkar, Z.X. Gong, A.S. Mujumdar, Melting of a phase change material in concentric horizontal annuli of arbitrary cross-section, Applied Thermal Engineering 20 (2000) 893 - 912. 


\section{List of tables}

Table 1: Thermophysical properties of PCM (A164), HTF (Hytherm) and Stainless steel Table 2: Source term definitions

\section{List of figures}

Figure 1: Organic Rankine Cycle (ORC) based concentrated solar power (CSP) plant Figure 2: (a) Front view and (b) side view of the LHTES with fins inside the HTF tubes. Numerical domain is shown by dotted line along with boundary conditions.

Figure 3: Comparison of Khillarkar et al. [39] and the present model: (a) solid liquid interface, (b) streamlines at $F o=0.1296$ (corresponds to $360 \mathrm{~s}$ ) and $R a=2.844 \times 10^{6}$

Figure 4: Grid independence study with three different grid sizes

Figure 5: Time evolution of (a) HTF outlet temperature for steel and PCM as a storage material (b) entropy generation and exergy input, (c) second law efficiency plot for PCM and steel Figure 6: Temperature contours at a cross-section located at $z=0.4 \mathrm{~m}$ for PCM at (a) $1800 \mathrm{~s}$, (b) $3600 \mathrm{~s}$ and steel at (c) $1800 \mathrm{~s}$, (d) $3600 \mathrm{~s}$

Figure 7: Variation in HTF outlet temperature with time for PCM and $\varepsilon=0.97,0.95,0.9$ and 0.85

Figure 8: Charging, discharging, and overall energy efficiency of PCM and $\varepsilon=0.97,0.95,0.9$ and 0.85

Figure 9: Temporal volumetric entropy generation for PCM and $\varepsilon=0.97,0.95,0.9$ and 0.85

Figure 10: Time evolution second law efficiency for PCM and $\varepsilon=0.97,0.95,0.9$ and 0.85

Figure 11: Charging and discharging second law efficiency of PCM and $\varepsilon=0.97,0.95,0.9$ and 0.85

Figure 12: Transient HTF outlet temperature for $d_{p}=0.33,0.5,1,2,3 \mathrm{~mm}$

Figure 13: Charging, discharging and overall energy efficiency for $d_{p}=0.33,0.5,1,2,3 \mathrm{~mm}$

Figure 14: Volumetric entropy generation for $d_{p}=0.33,0.5,1,2,3 \mathrm{~mm}$

Figure 15: Time evolution second law efficiency for $d_{p}=0.33,0.5,1,2,3 \mathrm{~mm}$

Figure 16: Charging and discharging second law efficiency for $d_{p}=0.33,0.5,1,2,3 \mathrm{~mm}$

Figure 17: Temperature contours at the cross sectional plane located at $z=0.4 \mathrm{~m}$ for $d_{p}=0.33$

$\mathrm{mm}$ at (a) $1800 \mathrm{~s}$, (b) $3600 \mathrm{~s}$ and $d_{p}=3 \mathrm{~mm}$ at (c) $1800 \mathrm{~s}$, (d) $3600 \mathrm{~s}$ 
Table 1: Thermophysical properties of PCM (A164), HTF (Hytherm) and Stainless steel

\begin{tabular}{cccc}
\hline & PCM (A164) & HTF (Hytherm 600) & SS316 \\
\hline$c_{p}(\mathrm{~J} / \mathrm{kg} . \mathrm{K})$ & 2013 & 3097.4 & 502.48 \\
$\rho\left(\mathrm{kg} / \mathrm{m}^{3}\right)$ & 1500 & 720.9 & 16 \\
$k(\mathrm{~W} / \mathrm{m} . \mathrm{K})$ & 0.425 & 0.116 & - \\
$\mu(\mathrm{kg} / \mathrm{m} . \mathrm{s})$ & 0.0063 & 0.0195 & - \\
$L_{\text {latent }}(\mathrm{J} / \mathrm{kg})$ & 249700 & - & - \\
$\beta\left(\mathrm{K}{ }^{-1}\right)$ & 0.00066 & - & - \\
$T_{m}\left({ }^{\circ} \mathrm{C}\right)$ & 168.7 & - & \\
\hline
\end{tabular}


Table 2: Source term definitions

\begin{tabular}{ccc} 
& $S_{r}$ & $-\frac{\mu}{K} u_{r}+\frac{\rho C}{\sqrt{K}}|u| u_{r}$ \\
& & $S_{\theta}$ \\
Momentum & $-\frac{\mu}{K} u_{\theta}+\frac{\rho C}{\sqrt{K}}|u| u_{\theta}$ \\
Equation & $S_{z}$ & $-\frac{\mu}{K} u_{z}+\frac{\rho C}{\sqrt{K}}|u| u_{z}+\rho g \beta\left(T_{l}-T_{m}\right)$ \\
\hline Energy & $S_{T l}$ & $h_{s l} a_{s l}\left(T_{s}-T_{l}\right)-\frac{\partial(\varepsilon \rho \Delta E)}{d t}$ \\
Equation & $S_{T s}$ & $h_{s l} a_{s l}\left(T_{l}-T_{s}\right)$ \\
\hline
\end{tabular}




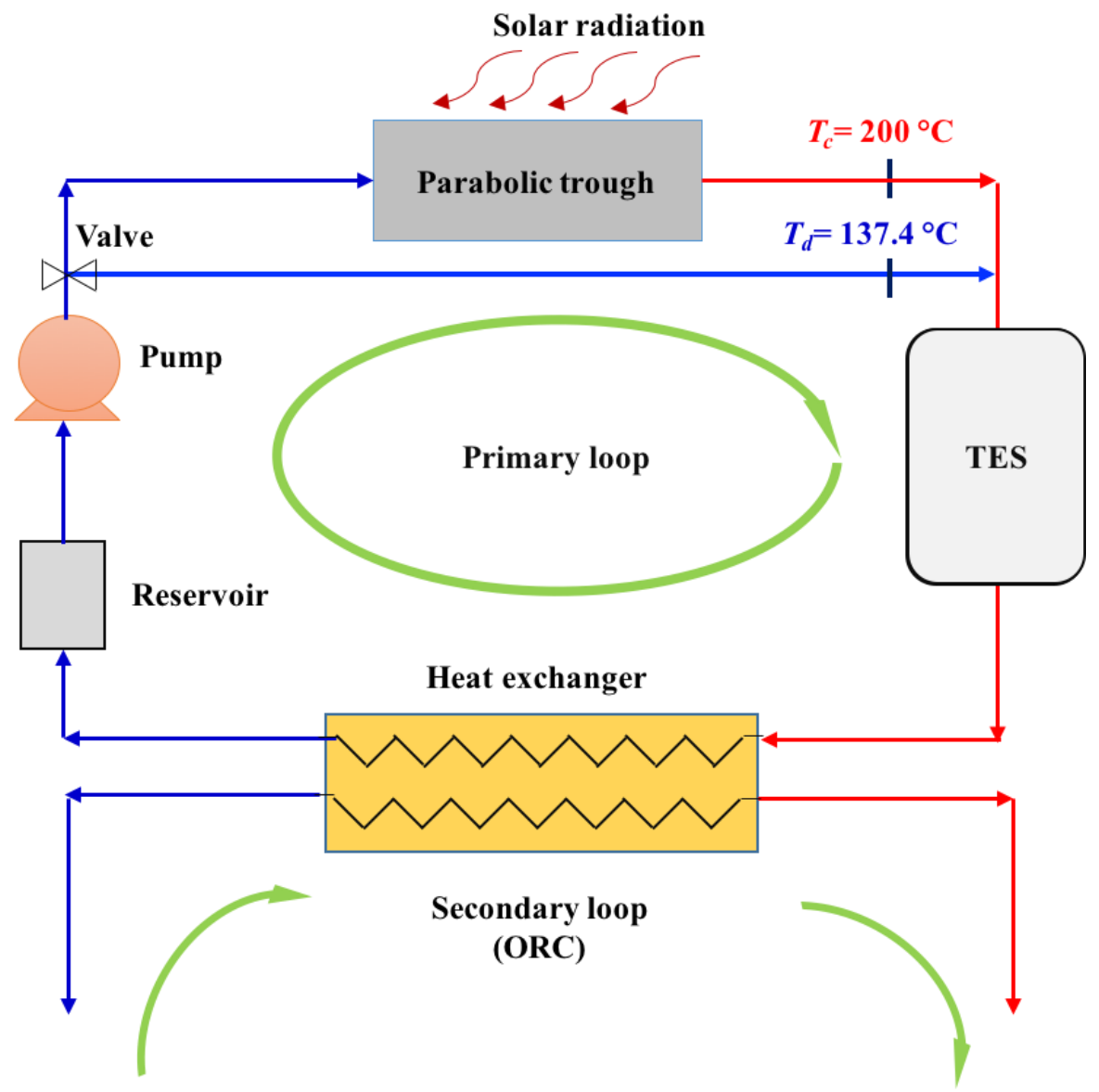

Figure 1: Organic Rankine Cycle (ORC) based concentrated solar power (CSP) plant 


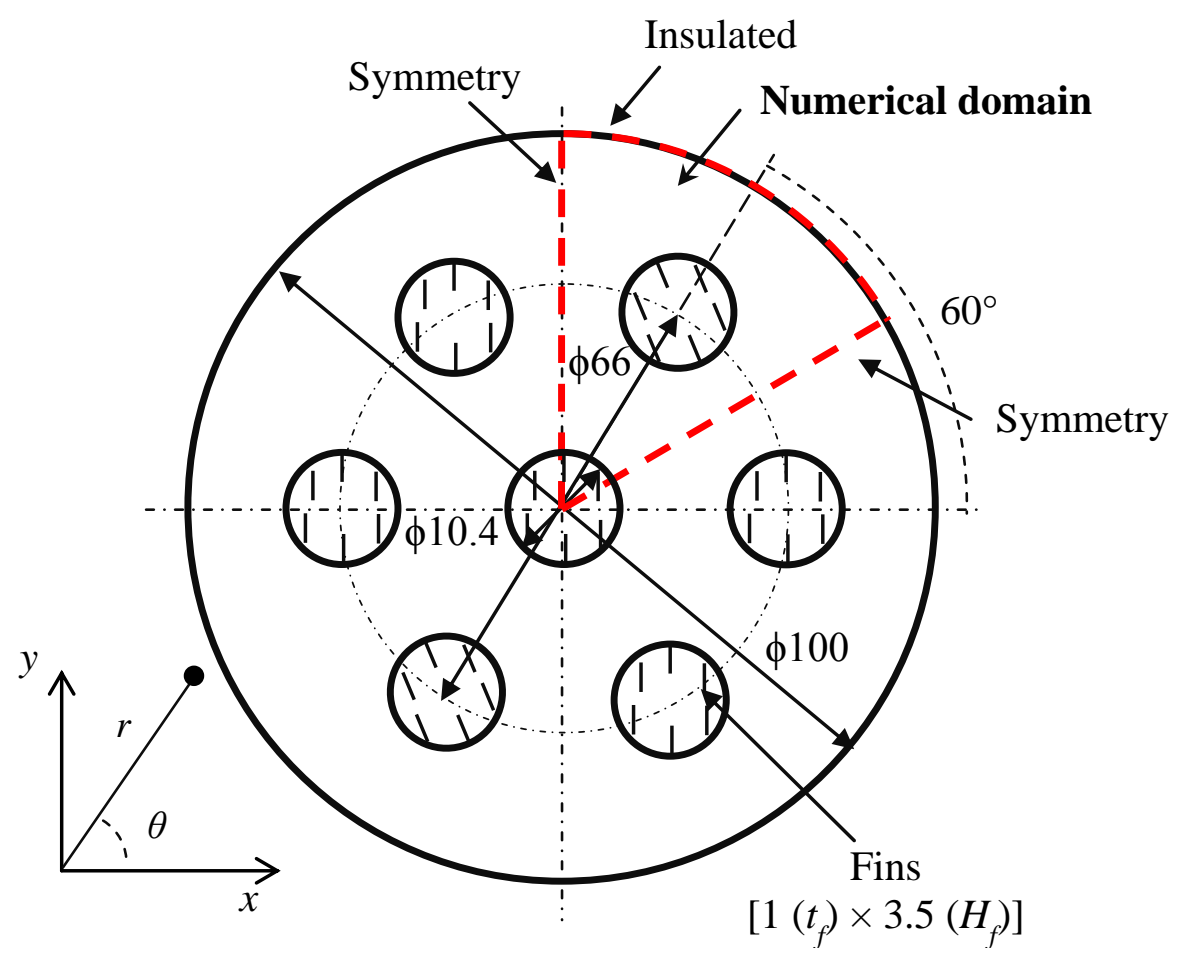

(a)

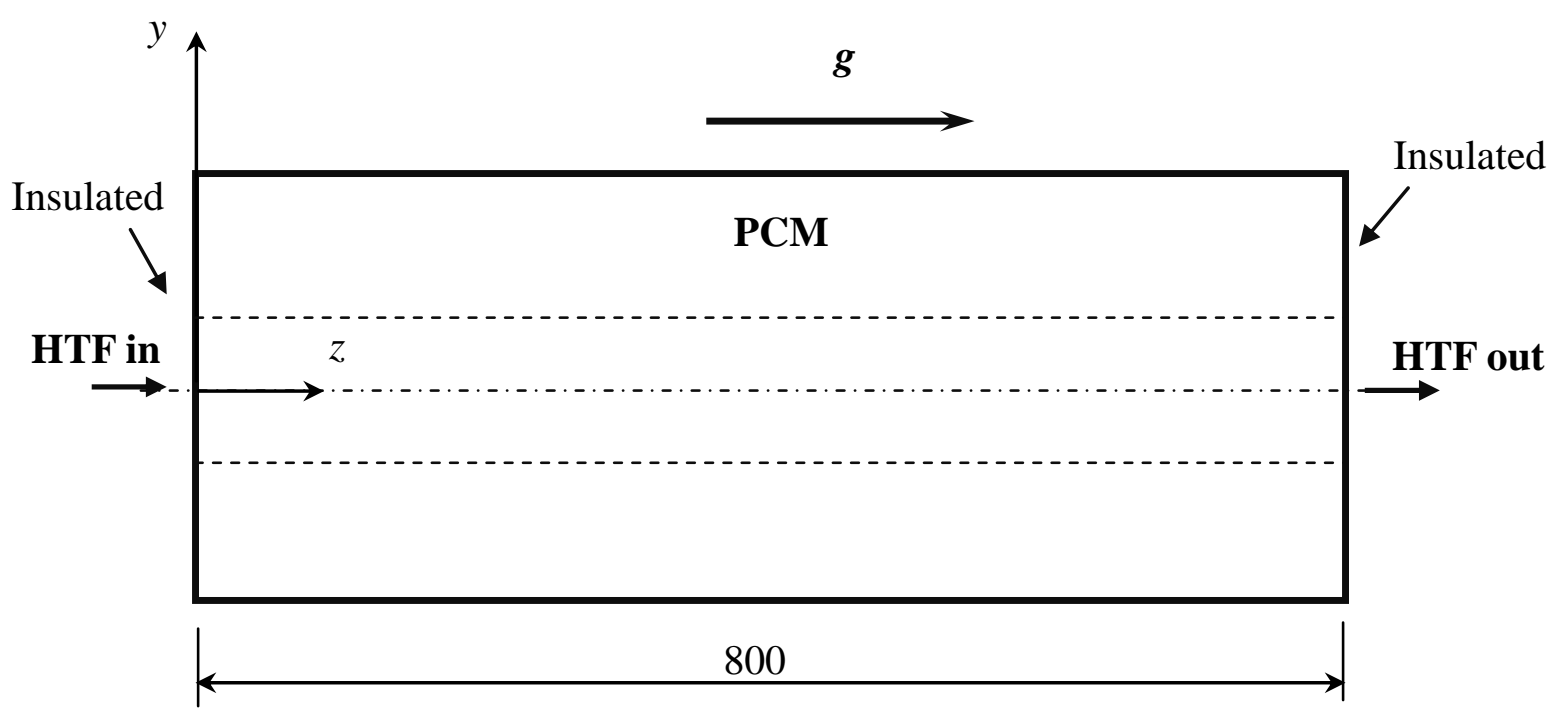

All the dimensions are in $\mathrm{mm}$

(b)

Figure 2: (a) Front view and (b) side view of the LHTES with fins inside the HTF tubes.

Numerical domain is shown by dotted line along with boundary conditions. 


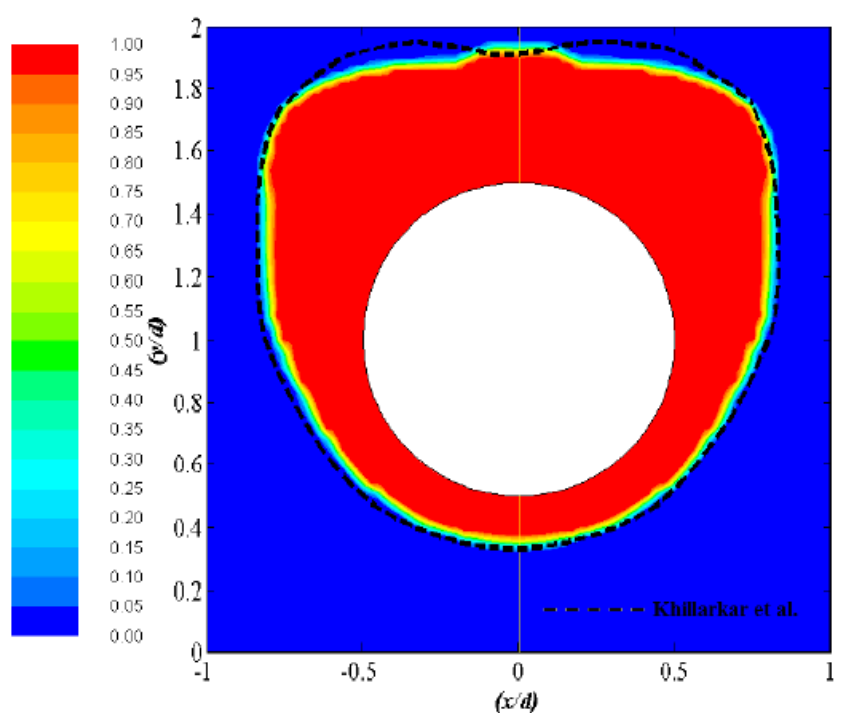

(a)

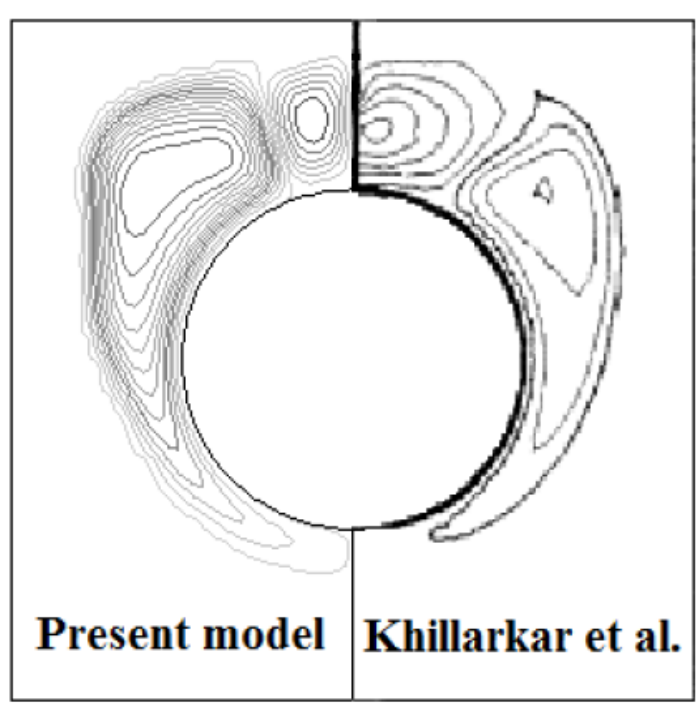

(b)

Figure 3: Comparison of Khillarkar et al. [39] and the present model: (a) solid liquid interface,

(b) streamlines at $F o=0.1296$ (corresponds to $360 \mathrm{~s}$ ) and $R a=2.844 \times 10^{6}$ 


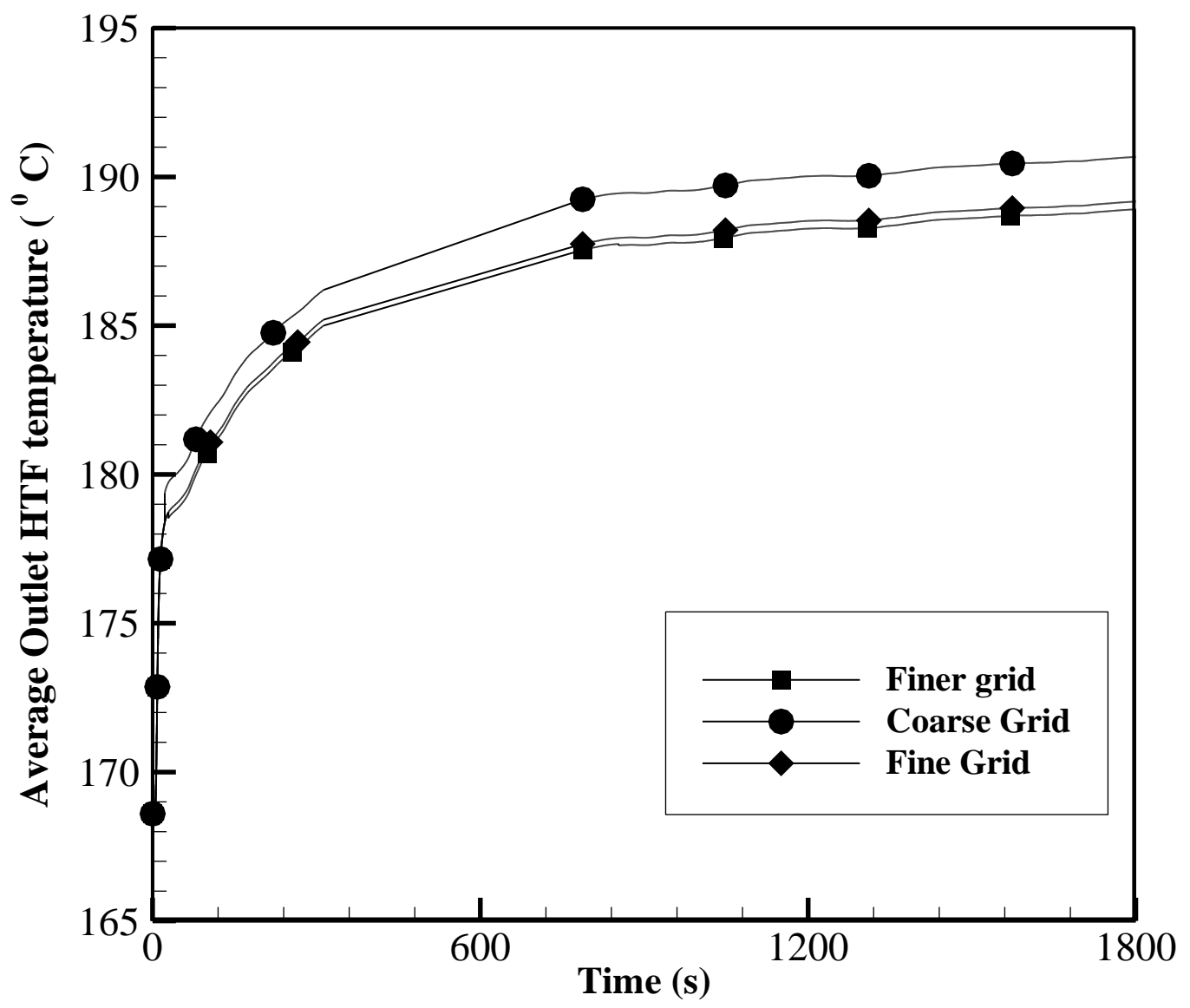

Figure 4: Grid independence study with three different grid sizes 


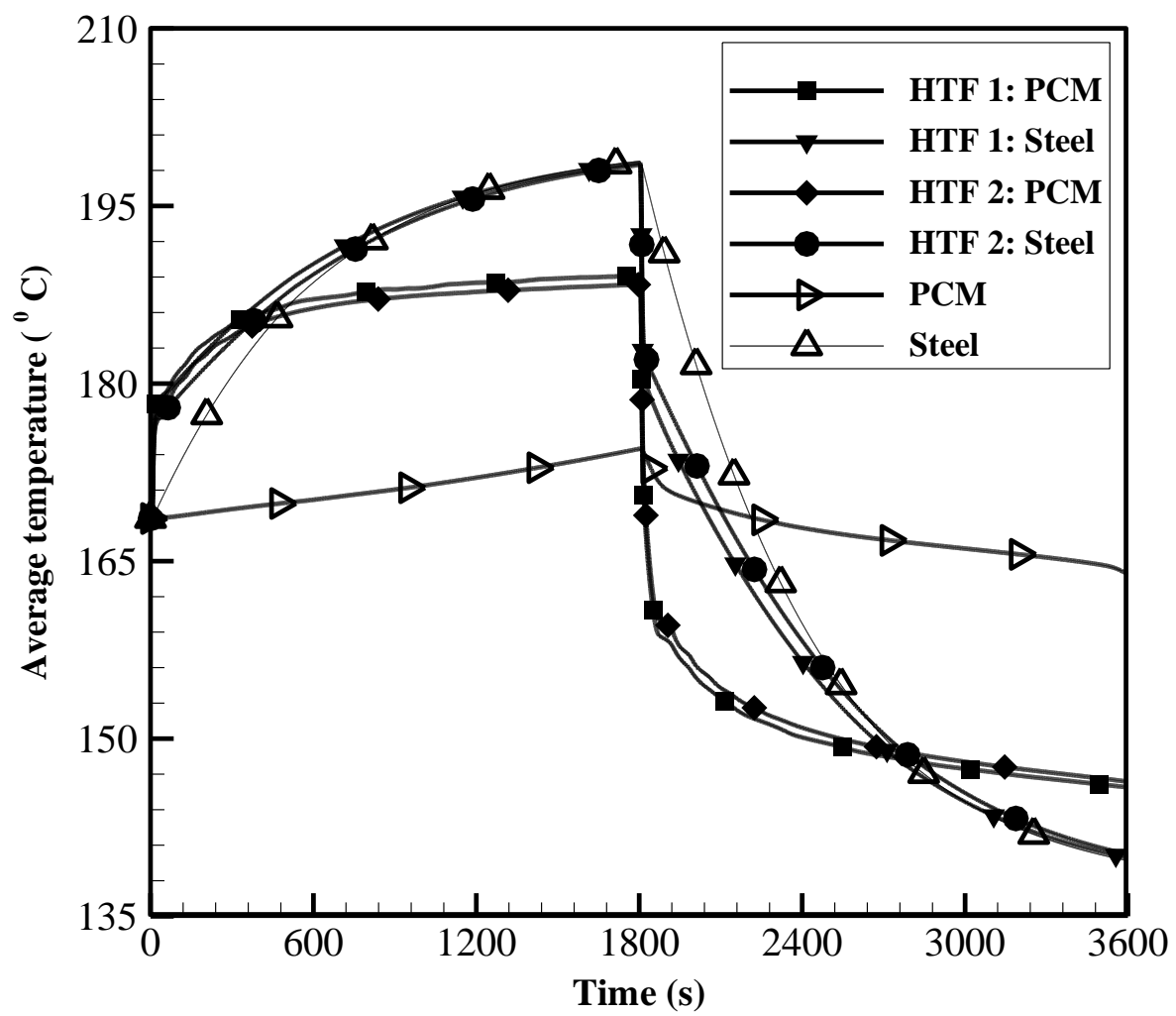

(a)

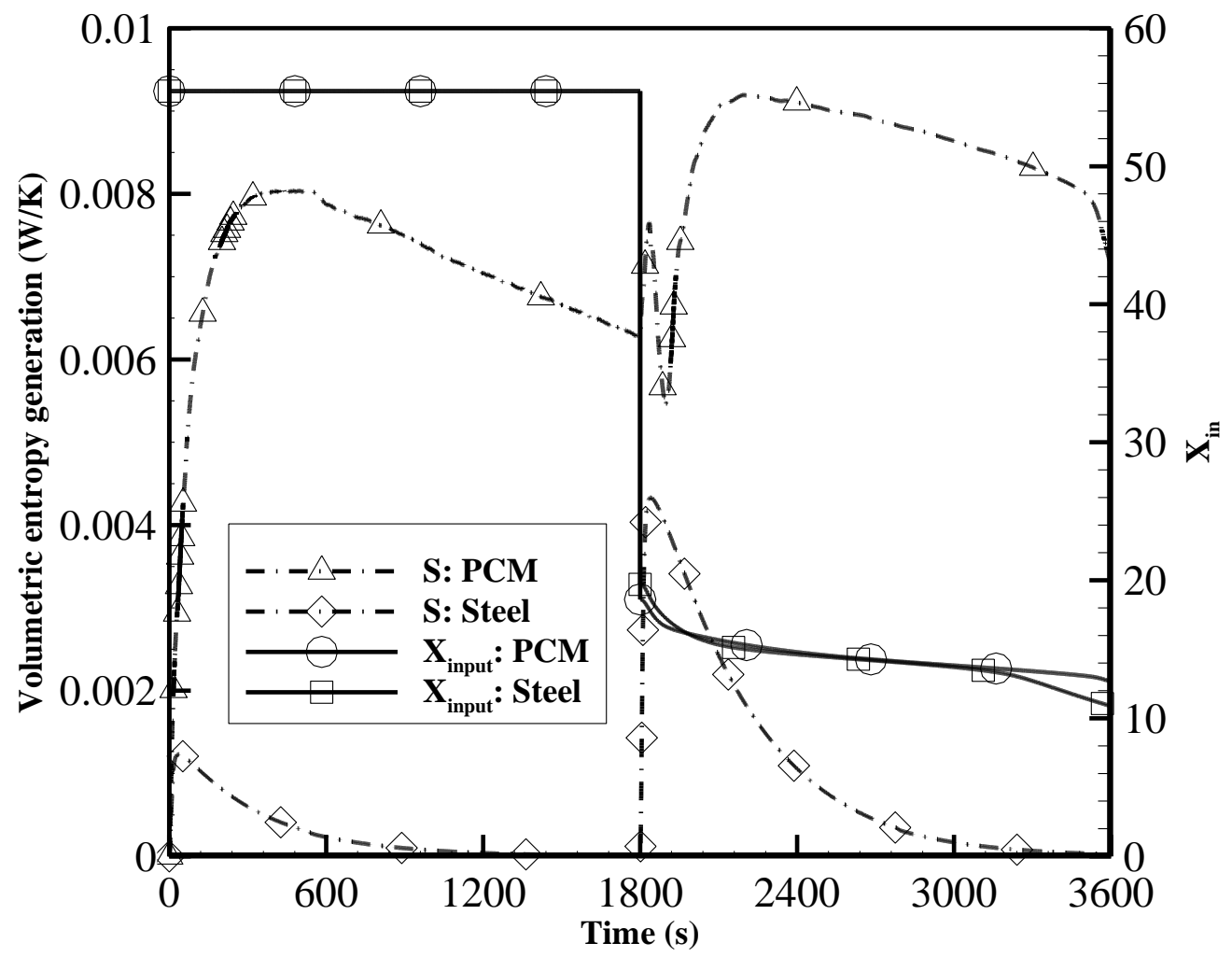

(b) 


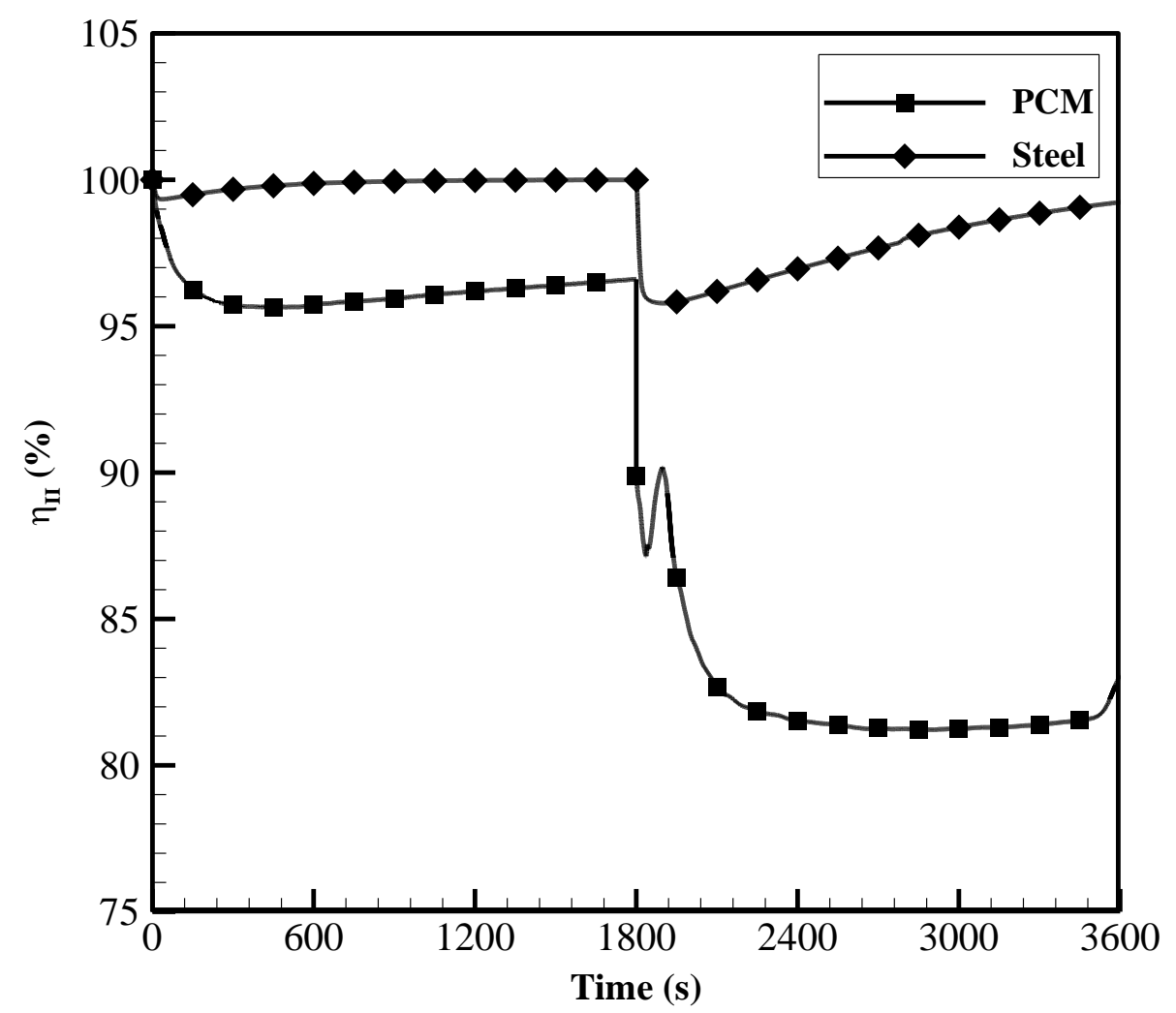

(c)

Figure 5: Time evolution of (a) HTF outlet temperature for steel and PCM as a storage material (b) entropy generation and exergy input, (c) second law efficiency plot for PCM and steel 


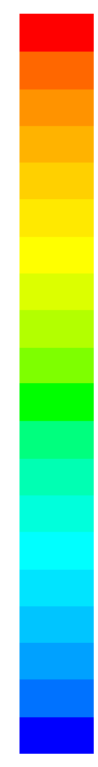

200.00

198.40

196.80

195.20

193.60

192.00

190.40

188.80

187.20

185.60

184.00

182.40

180.80

179.20

177.60

176.00

174.40

172.80

171.20

169.60

168.00
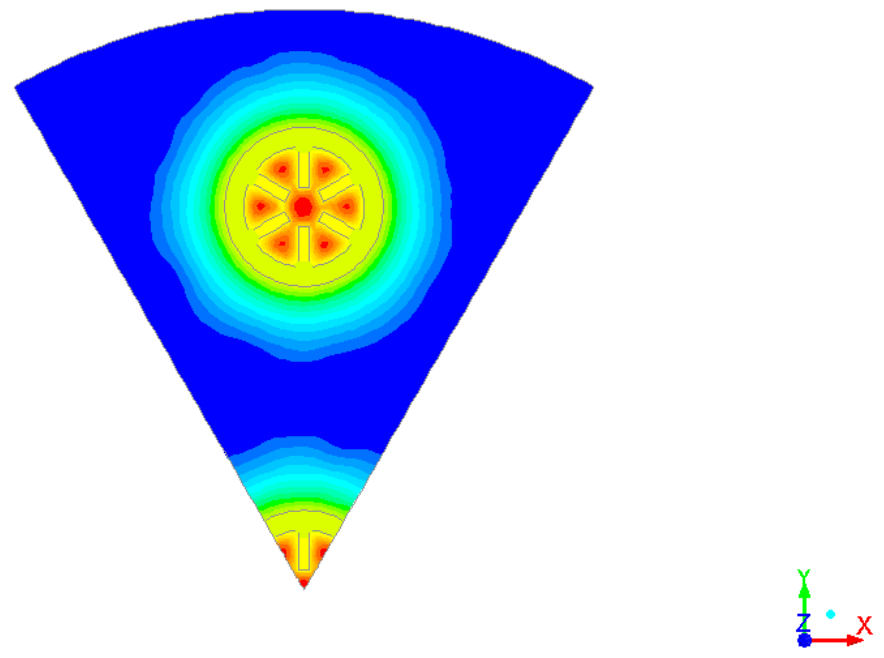

(a)

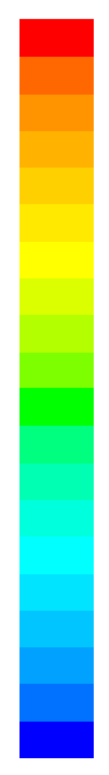

169.00

167.40

165.80

164.20

162.60

161.00

159.40

157.80

156.20

154.60

153.00

151.40

149.80

148.20

146.60

145.00

143.40

141.80

140.20

138.60

137.00
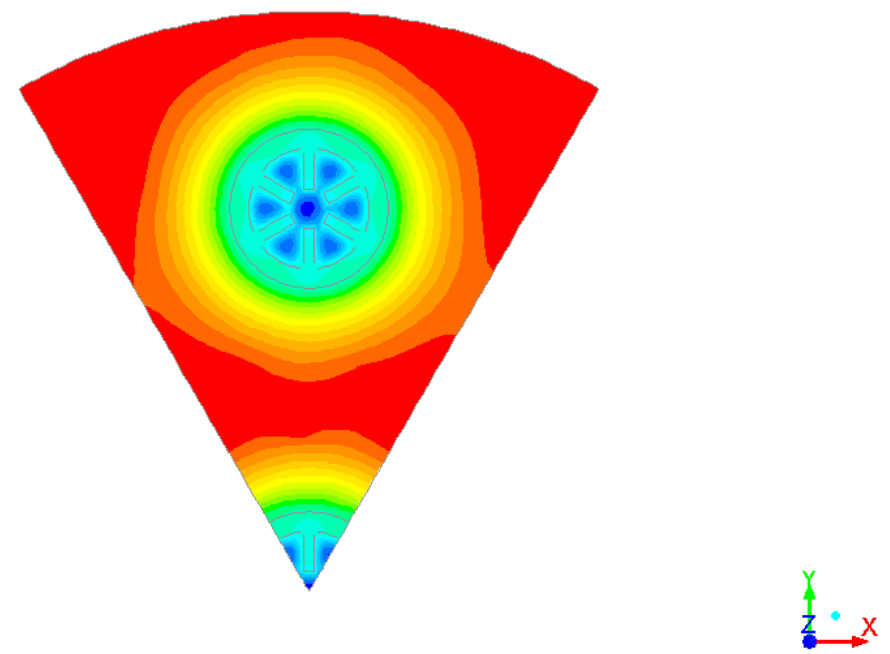

(b) 

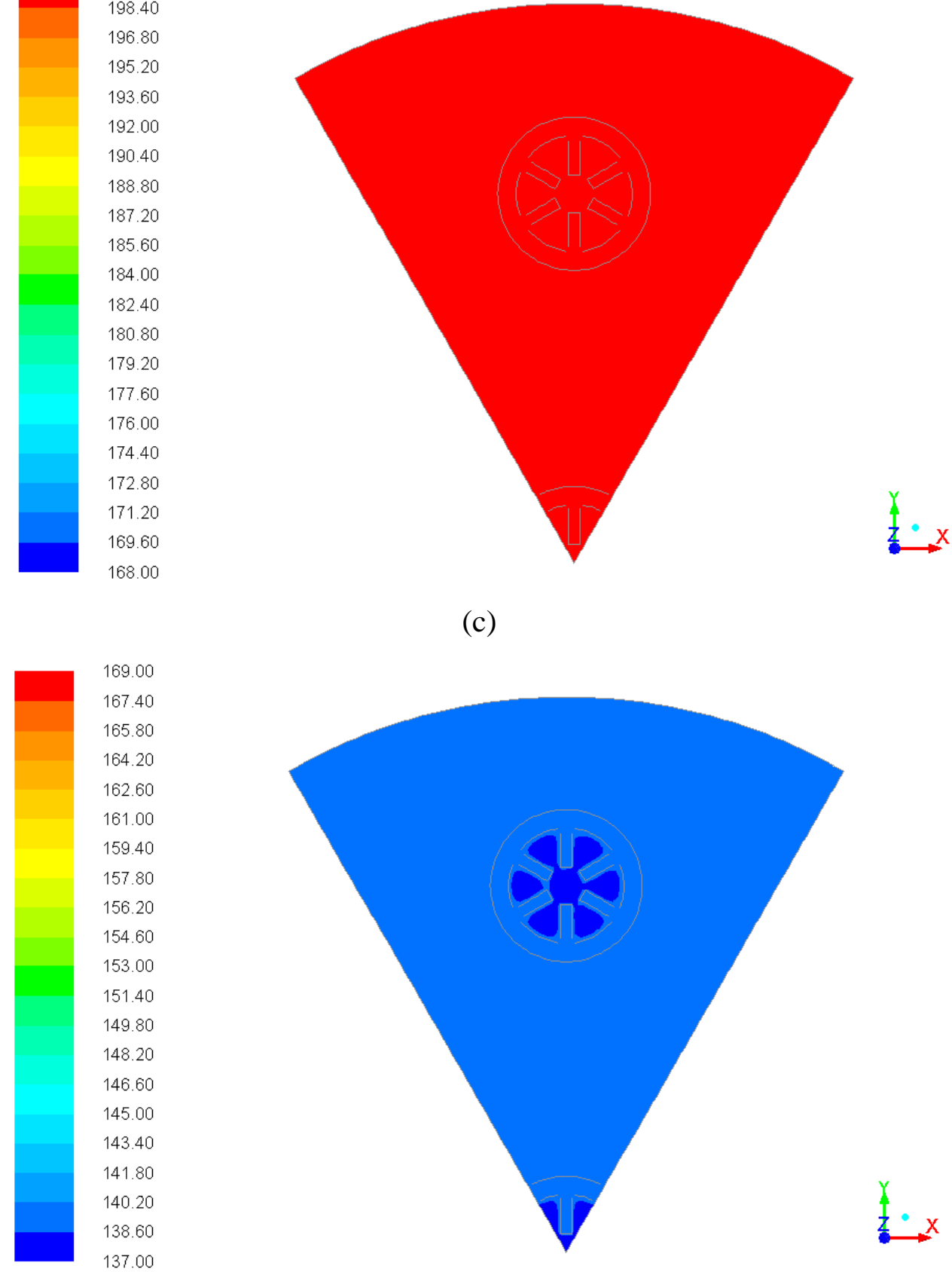

169.00

167.40

165.80

164.20

162.60

161.00

159.40

157.80

156.20

154.60

153.00

151.40

149.80

148.20

146.60

145.00

143.40

141.80

140.20

138.60

137.00 (c)
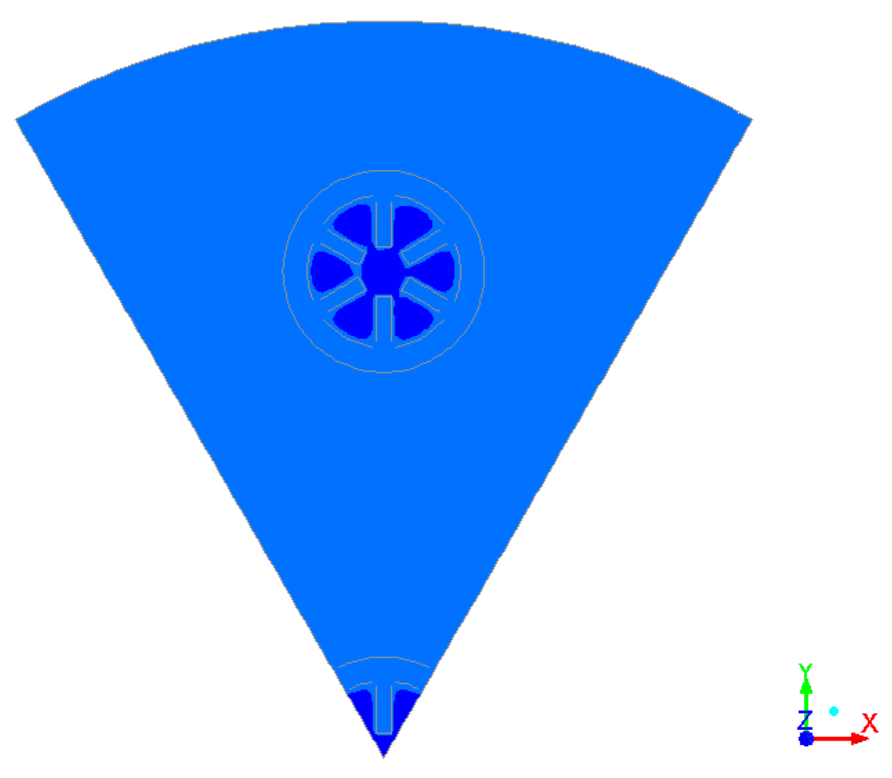

(d)

Figure 6: Temperature contours at a cross-section located at $z=0.4 \mathrm{~m}$ for PCM at (a) $1800 \mathrm{~s}$, (b) $3600 \mathrm{~s}$ and steel at (c) $1800 \mathrm{~s}$, (d) $3600 \mathrm{~s}$ 


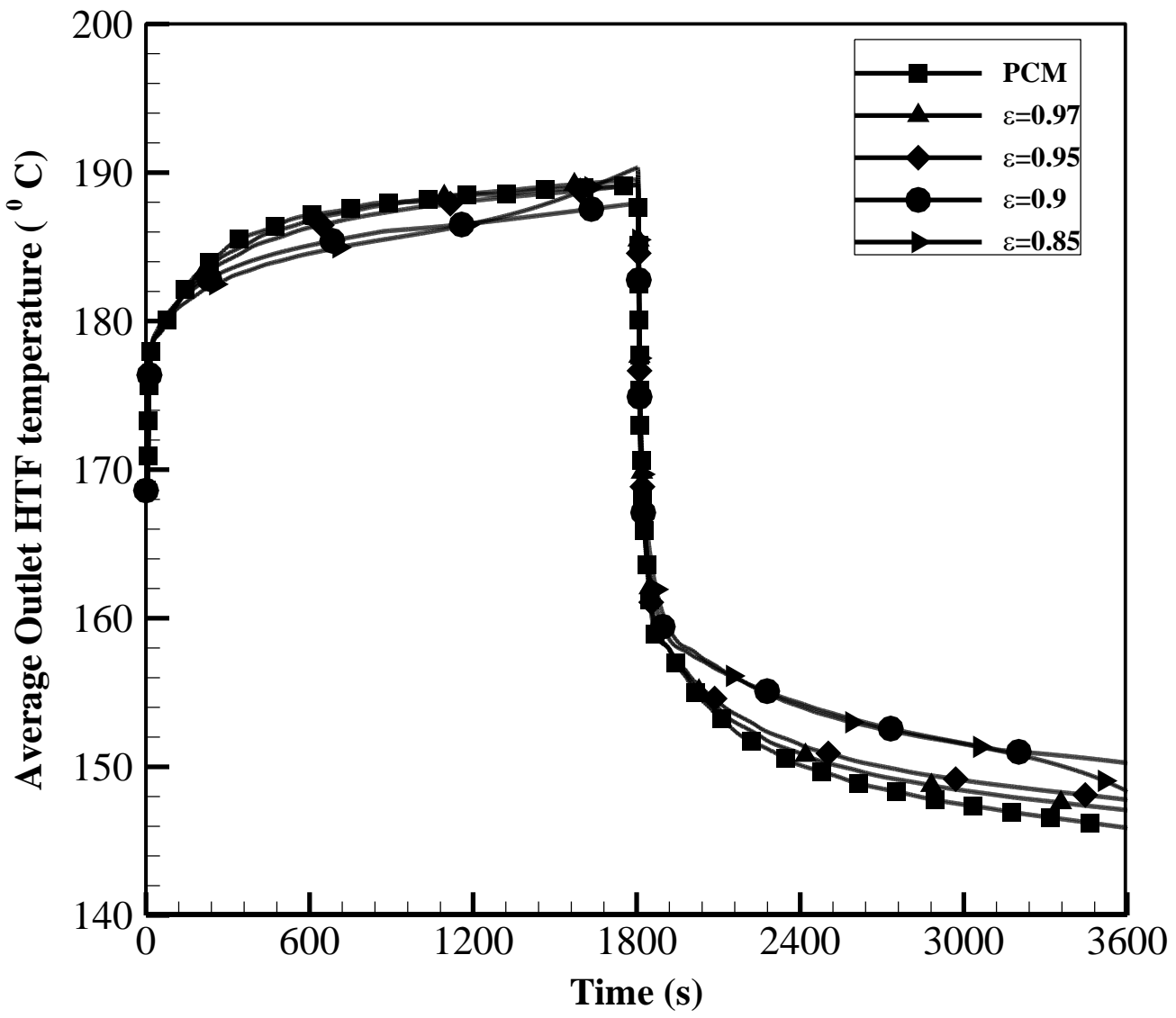

Figure 7: Variation in HTF outlet temperature with time for PCM and $\varepsilon=0.97,0.95,0.9$ and 0.85 


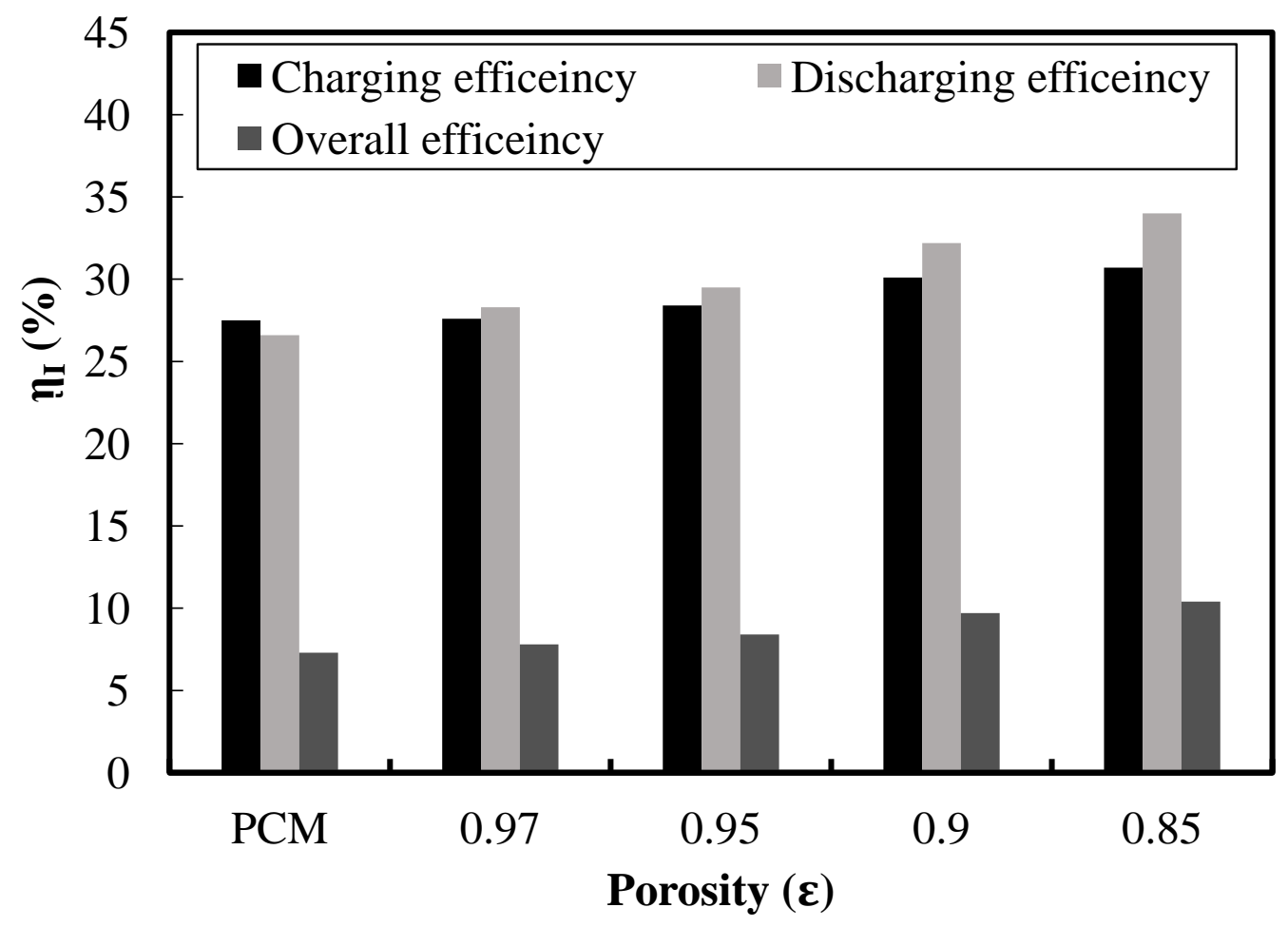

Figure 8: Charging, discharging, and overall energy efficiency of PCM and $\varepsilon=0.97,0.95,0.9$ and 0.85 


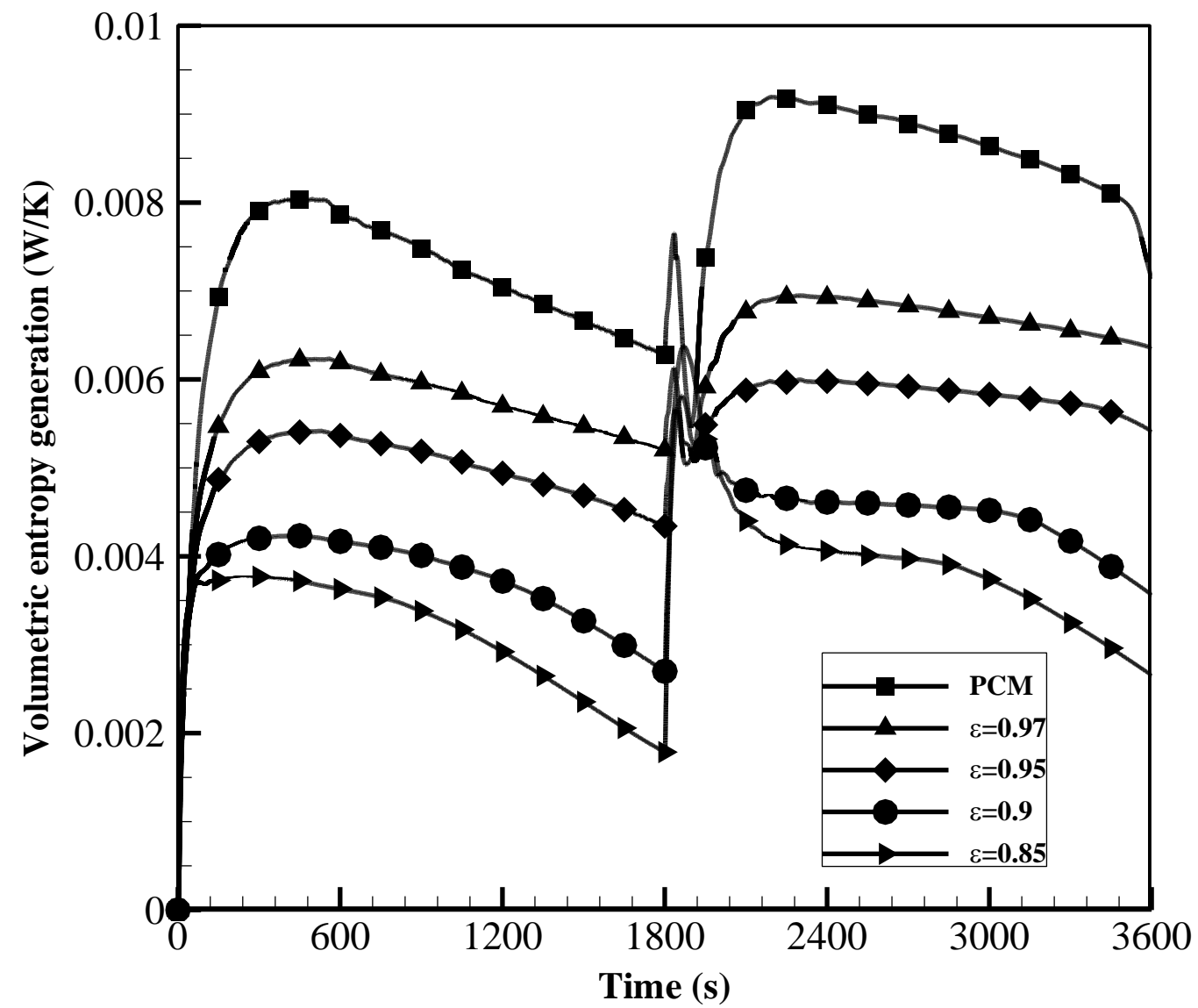

Figure 9: Temporal volumetric entropy generation for PCM and $\varepsilon=0.97,0.95,0.9$ and 0.85 


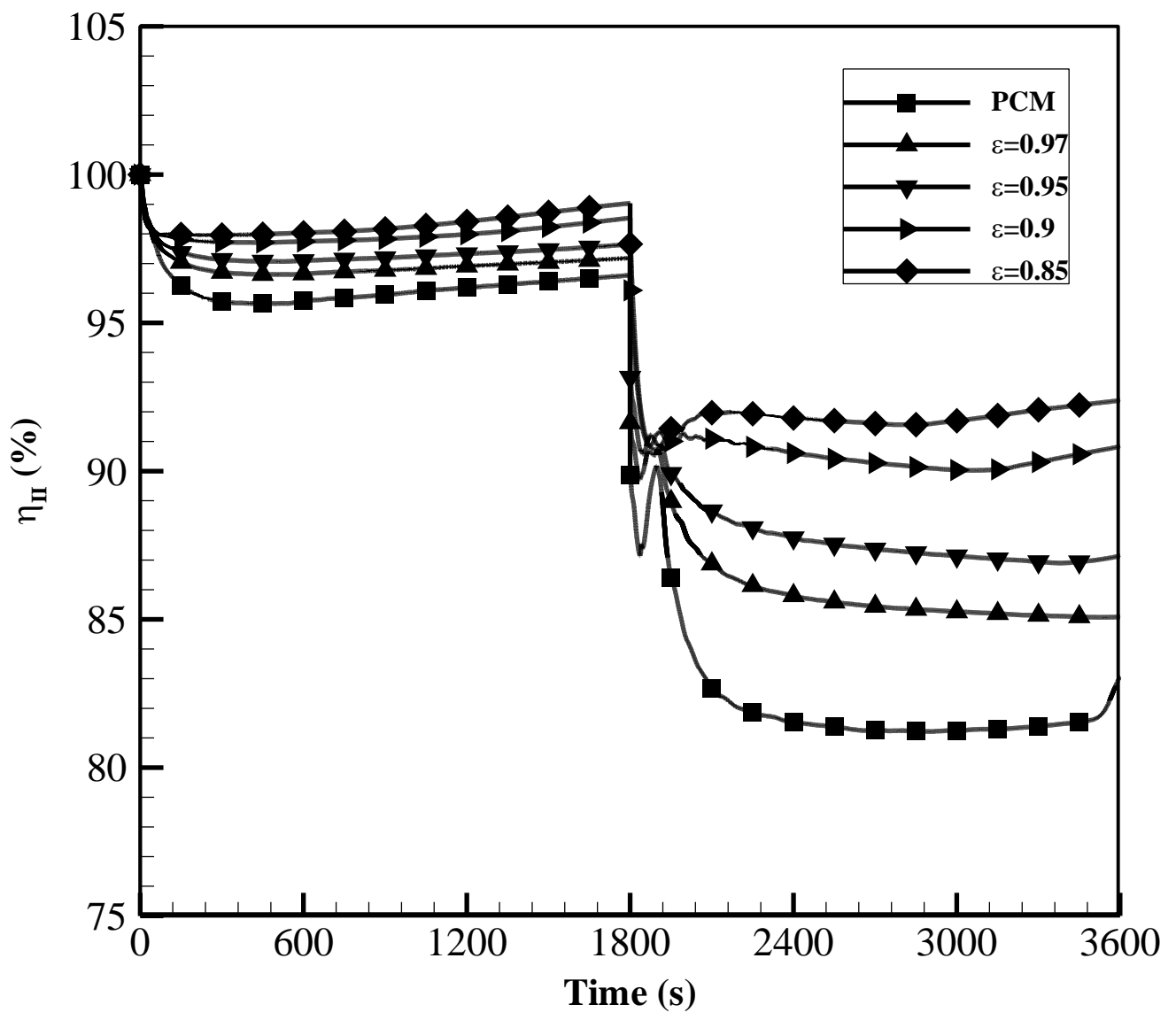

Figure 10: Time evolution second law efficiency for PCM and $\varepsilon=0.97,0.95,0.9$ and 0.85 


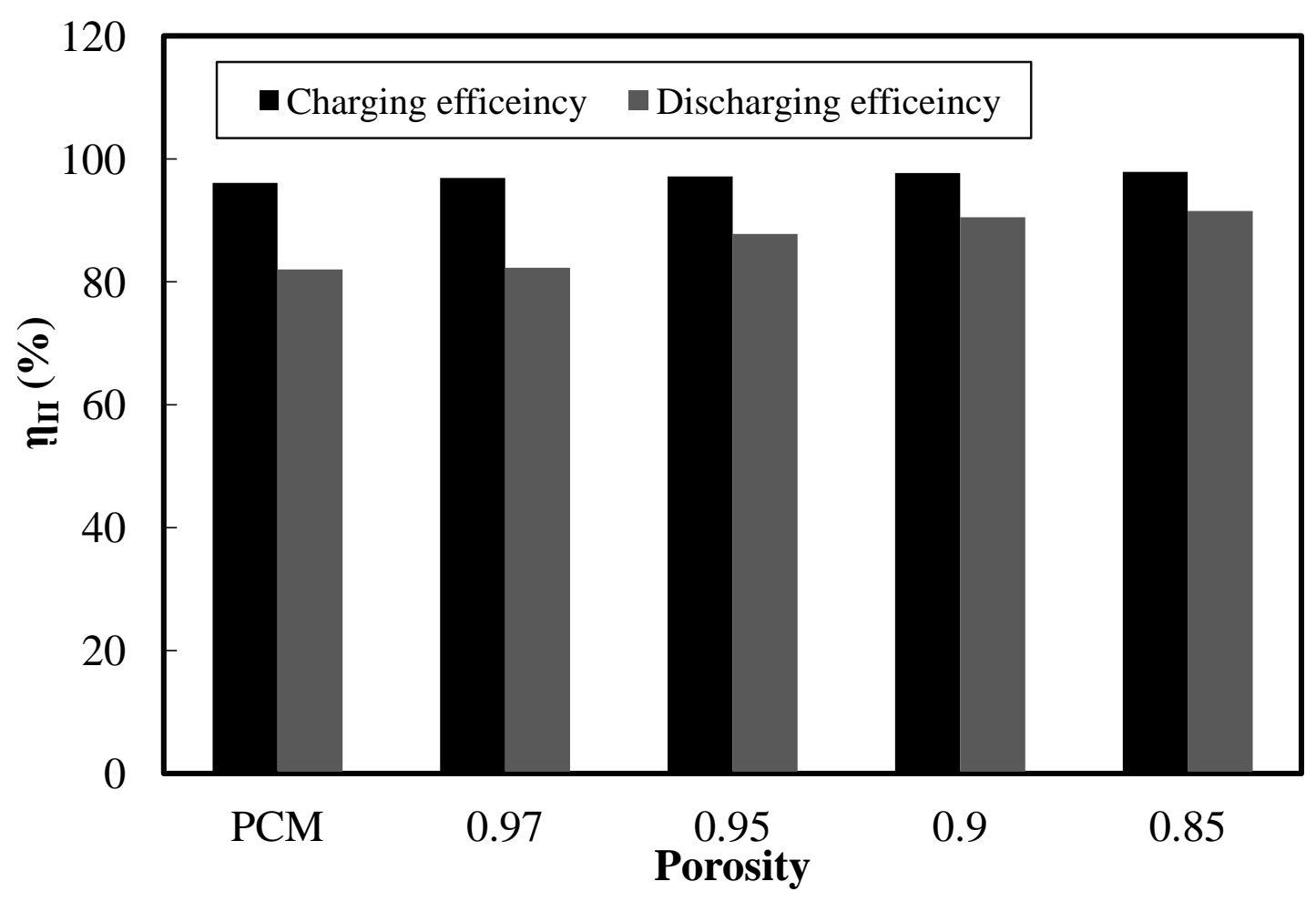

Figure 11: Charging and discharging second law efficiency of PCM and $\varepsilon=0.97,0.95,0.9$ and 0.85 


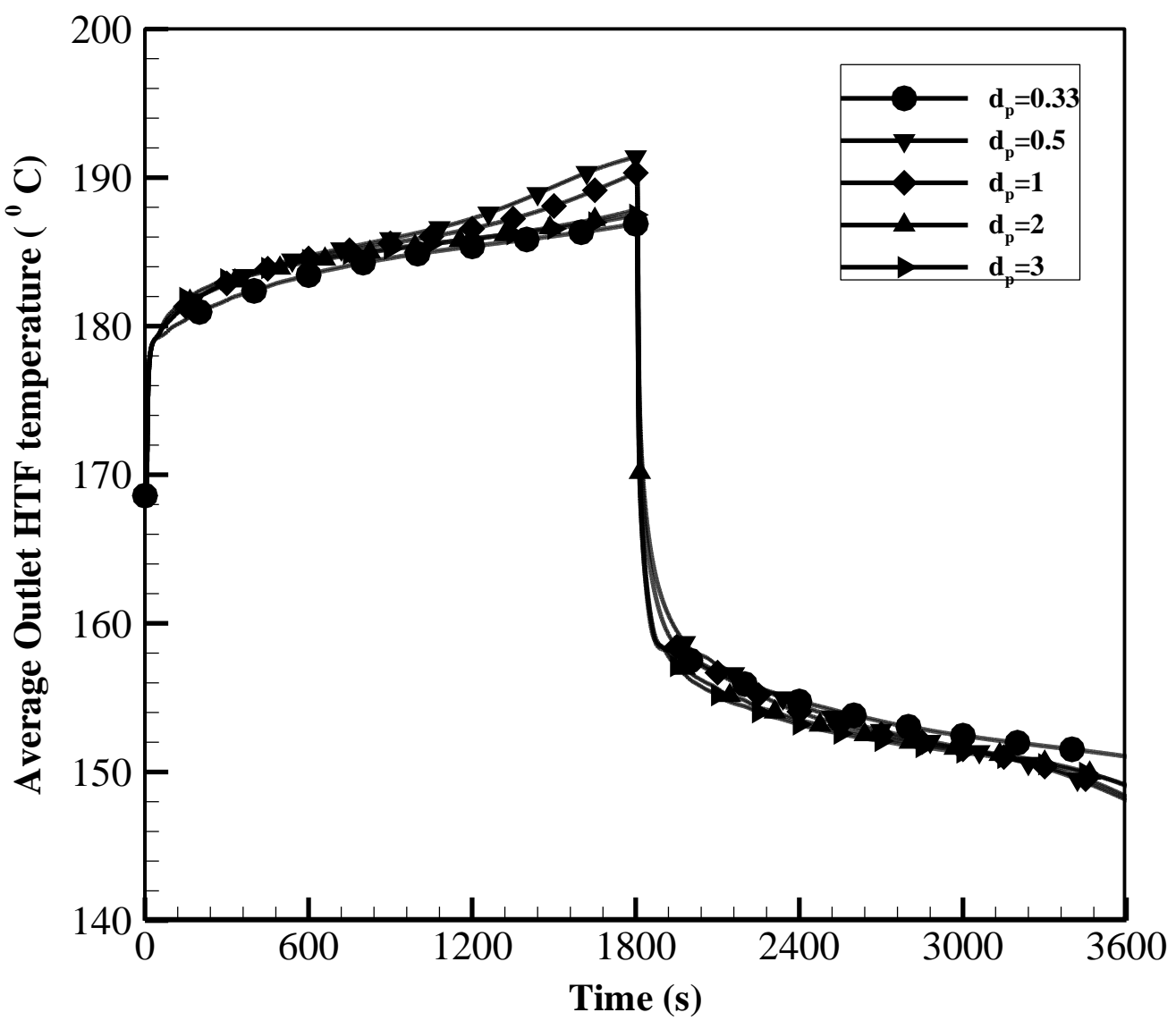

Figure 12: Transient variation of HTF outlet temperature for $d_{p}=0.33,0.5,1,2,3 \mathrm{~mm}$ 


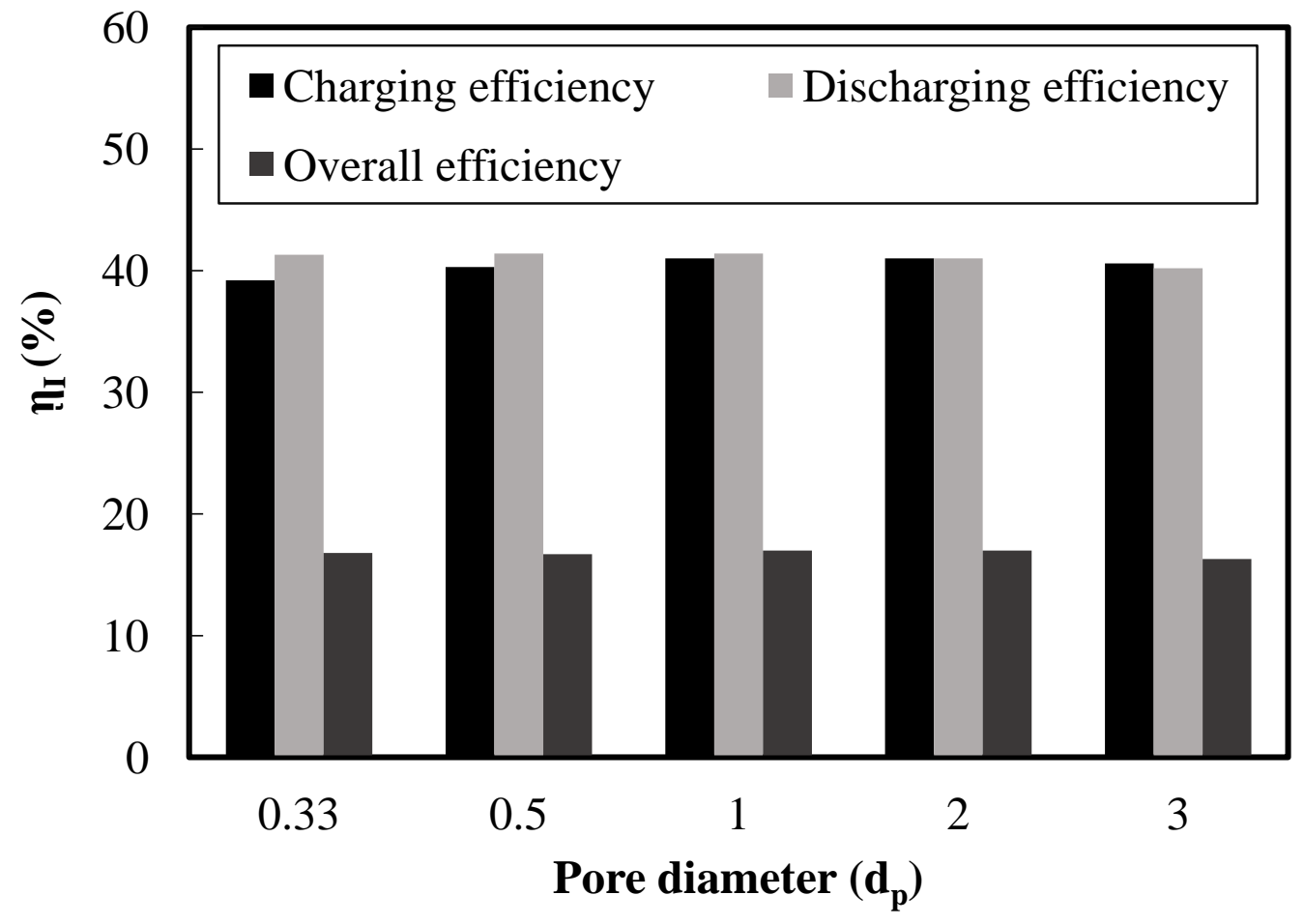

Figure13: Charging, discharging and overall energy efficiency for $d_{p}=0.33,0.5,1,2,3 \mathrm{~mm}$ 


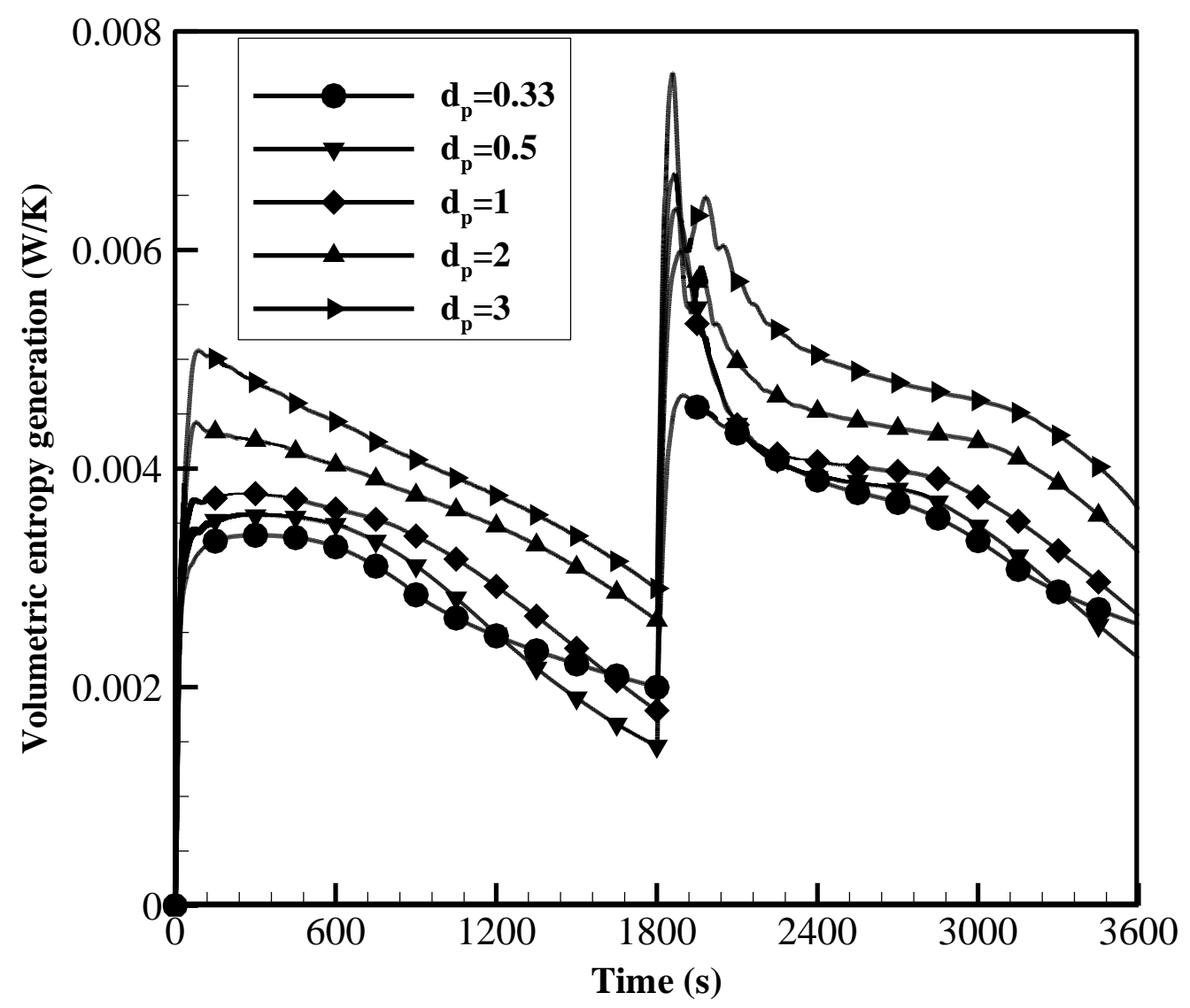

Figure 14: Volumetric entropy generation for $d_{p}=0.33,0.5,1,2,3 \mathrm{~mm}$ 


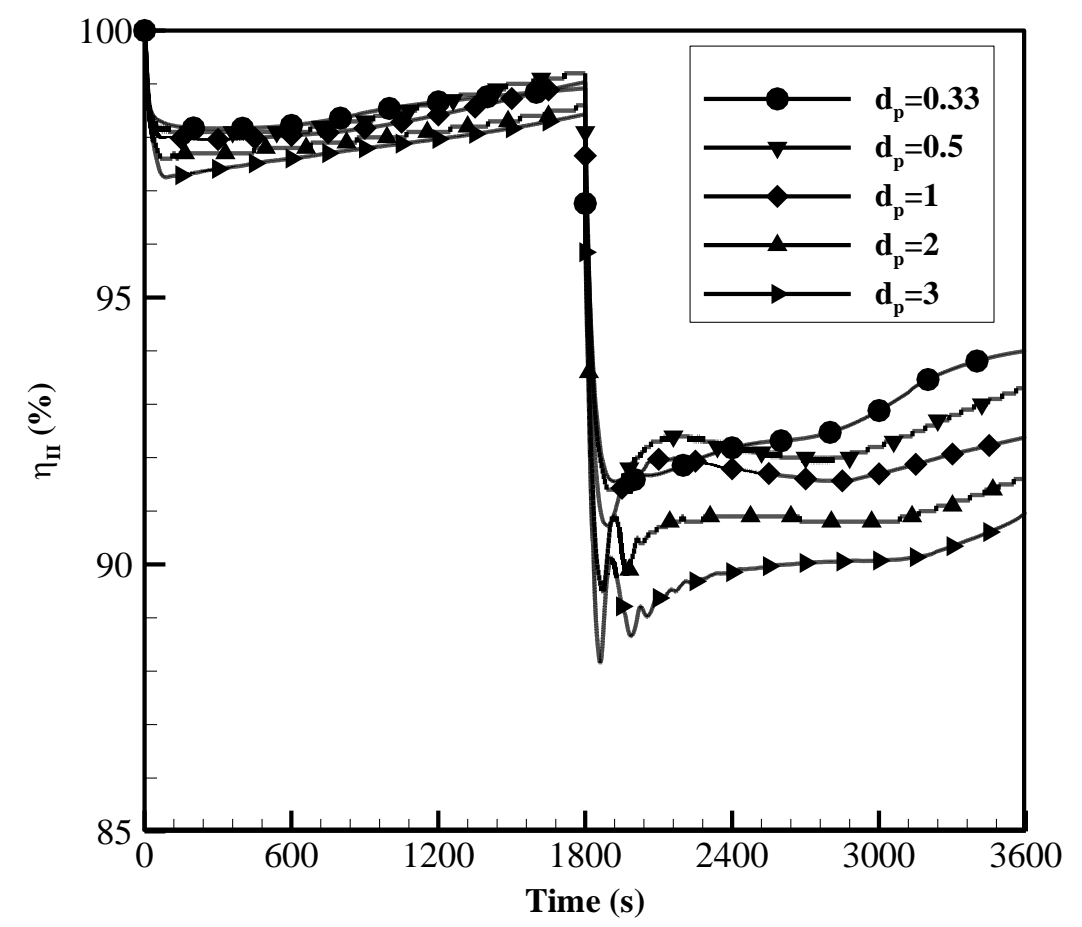

Figure 15: Time evolution second law efficiency for $d_{p}=0.33,0.5,1,2,3 \mathrm{~mm}$

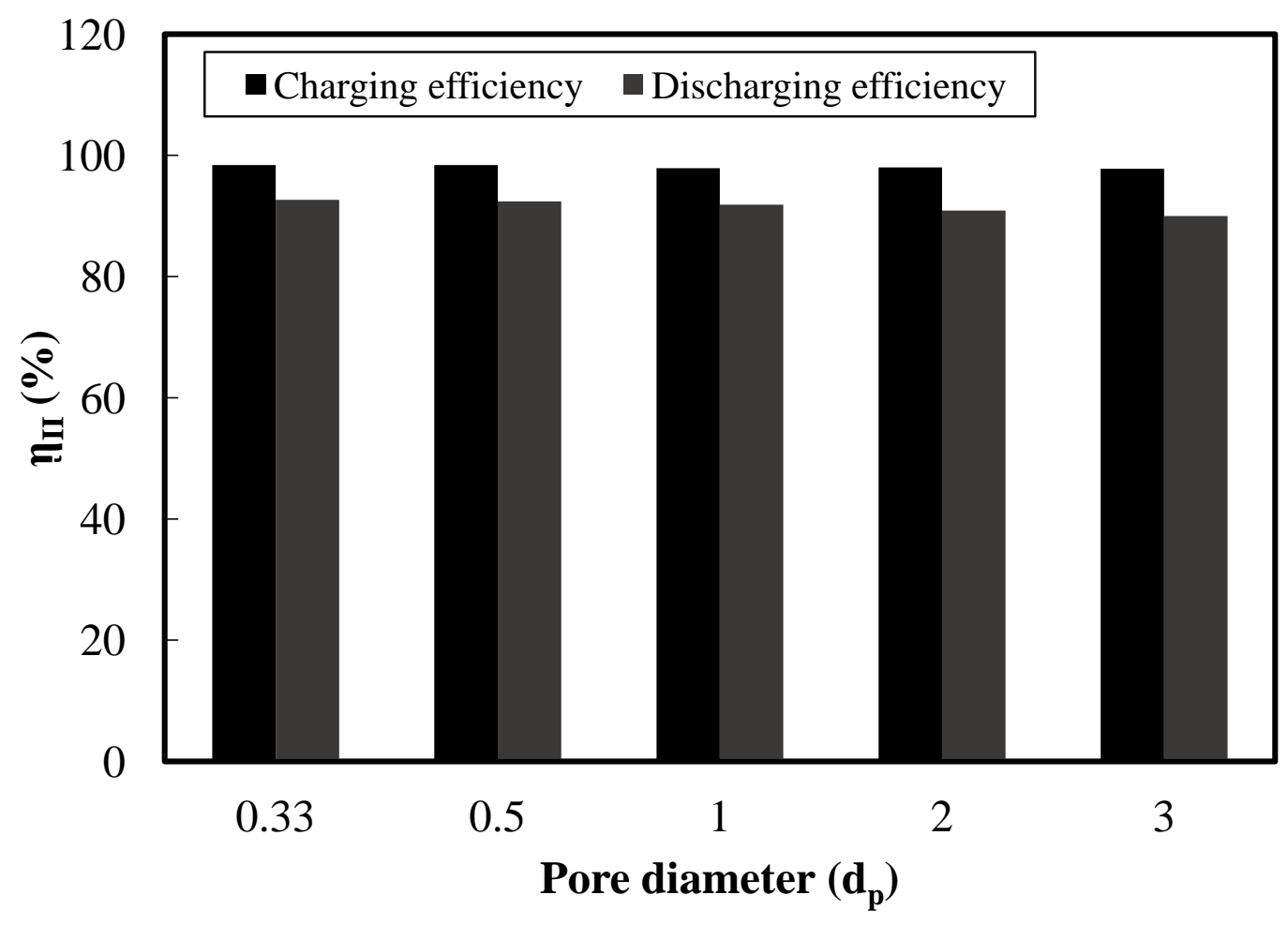

Figure 16: Charging and discharging second law efficiency for $d_{p}=0.33,0.5,1,2,3 \mathrm{~mm}$ 

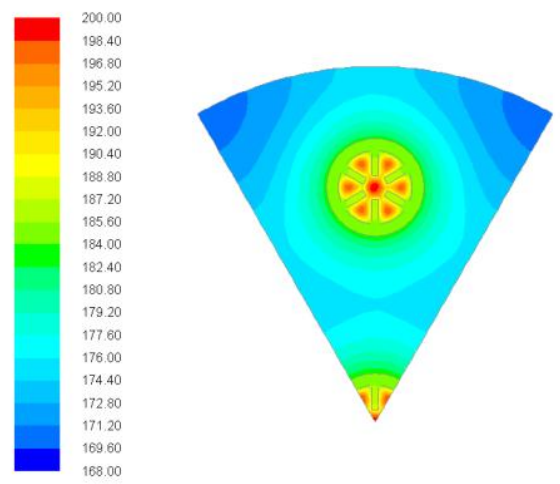

(a)

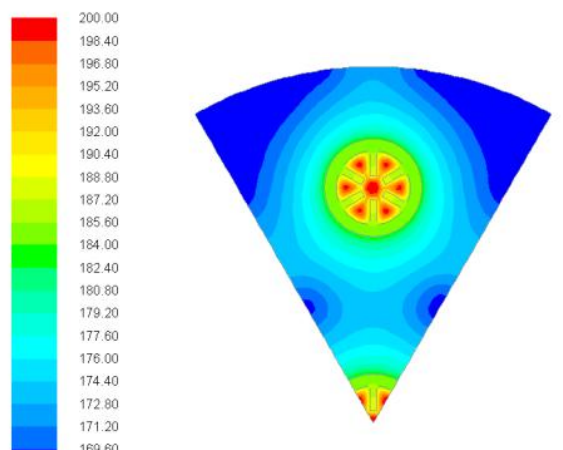

(c)
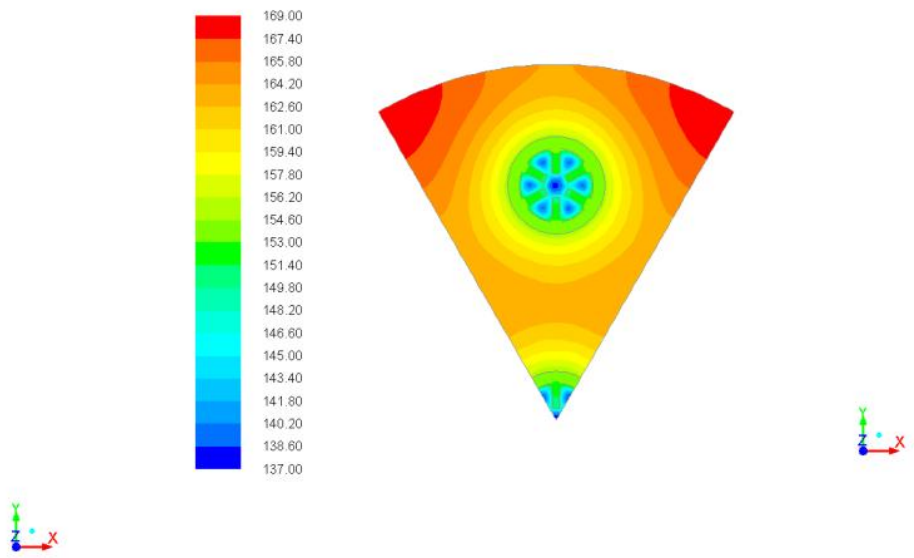

(b)
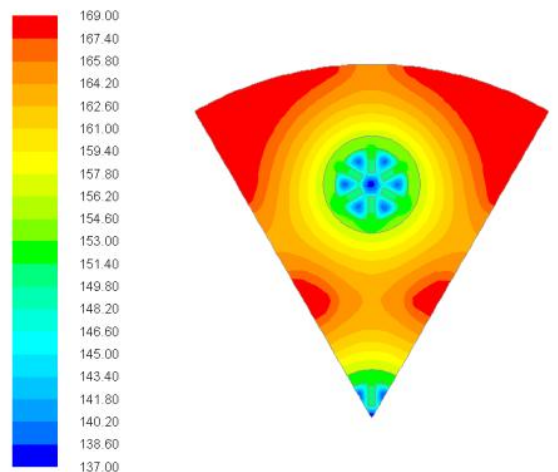

$\underset{+\infty}{\stackrel{x}{x} x}$

Figure 17: Temperature contours at the cross sectional plane located at $z=0.4 \mathrm{~m}$ for $d_{p}=0.33$ $\mathrm{mm}$ at (a) $1800 \mathrm{~s}$, (b) $3600 \mathrm{~s}$ and $d_{p}=3 \mathrm{~mm}$ at (c) $1800 \mathrm{~s}$, (d) $3600 \mathrm{~s}$ 


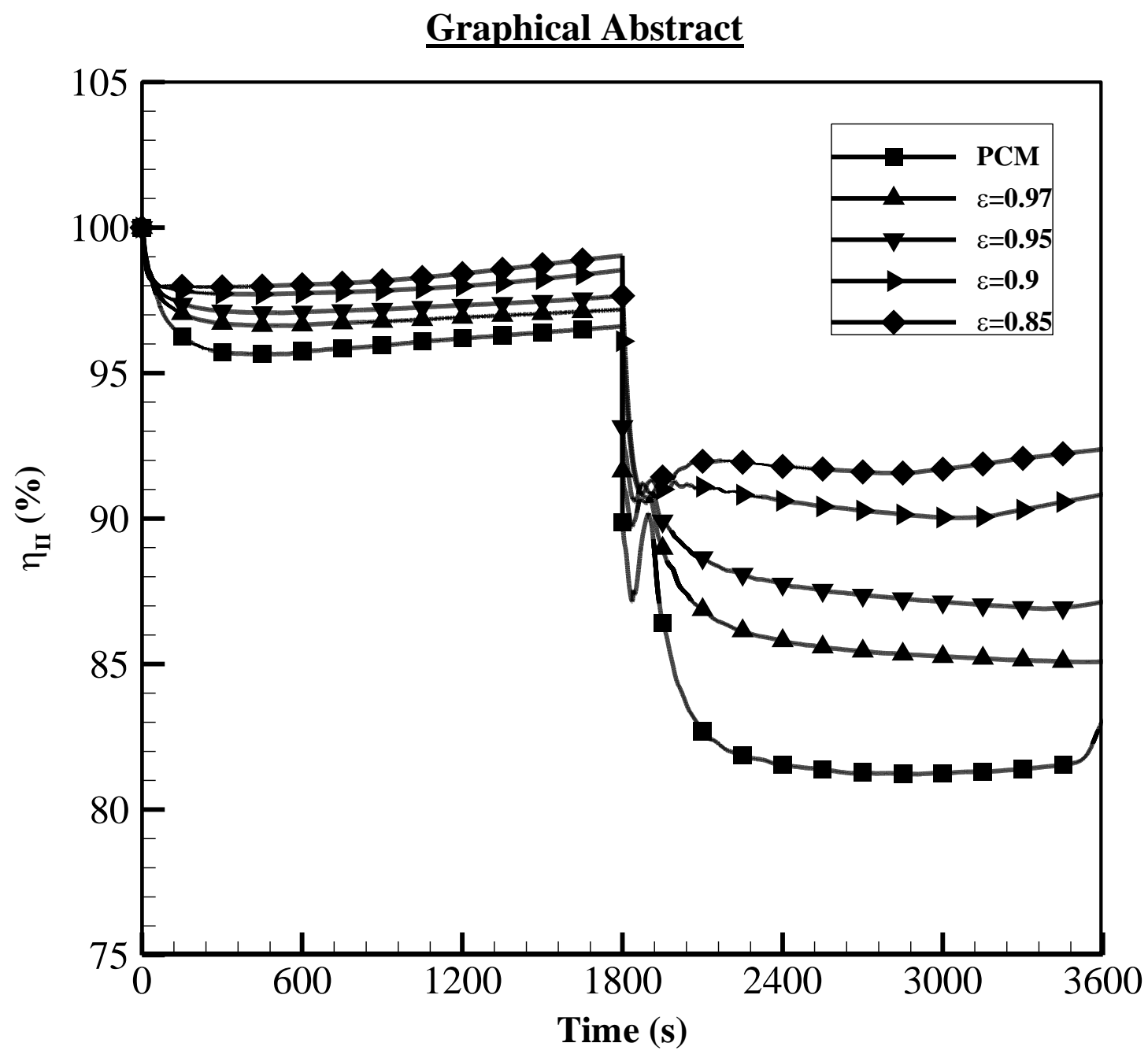

I. Metal matrix is used as the thermal conductivity enhancers (TCE) in PCM-based TES.

II. Time evolution second law analysis is evaluated for different porosities and pore diameters.

III. Reduction in fluctuation in HTF temperature is significantly affected by the change in porosity $(\varepsilon)$ shown in figure.

IV. Maximum energy and exergy efficiencies are obtained for porosity of 0.85 .

V. Effect of pore diameter on first law and second law efficiencies is found to be marginal. 